\title{
Pautas y recomendaciones técnico-jurídicas para la configuración de un canal de denuncias eficaz en organizaciones públicas y privadas. La perspectiva española" Technical and legal guidelines and recommendations for the creation of effective complaints channels in public and private organizations. The Spanish perspective
}

\section{JULIO BALLESTEROS SÁNCHEZ* Universidad de Salamanca (España)}

Resumen: Este artículo parte de una premisa básica: en los últimos años, se han descubierto multitud de casos graves de corrupción que han afectado la credibilidad de las Administraciones públicas, pero también la del sector privado. Sectores como el urbanismo o la contratación pública han sido prolijos en cuanto al acontecimiento de actividades criminales que socavan el buen funcionamiento de la Administración pública y la actividad empresarial con base en la ética y la legalidad. En consecuencia, se considera fundamental implementar mecanismos internos de denuncia para mejorar las organizaciones (públicas y privadas), descubriendo prematuramente conductas ilícitas y, a su vez, identificando a las personas naturales responsables de tales hechos. De la misma manera, para las empresas, la constatación de la eficacia de los canales de denuncia en sede judicial coadyuva a las defensas corporativas en el logro de la exención de la responsabilidad penal. Por ello, desde una perspectiva técnica, se ofrecen pautas y recomendaciones a partir del estudio de distintas regulaciones para el incremento de la eficacia de estos canales y para la reducción de la inseguridad jurídica que acontece en España, ante la parca redacción del Código Penal. Asimismo, se aborda el anonimato, la delación remunerada y la protección del denunciante frente a represalias.

Palabras clave: Denunciantes internos, delincuencia corporativa, programas de cumplimiento, cumplimiento normativo público, prevención, España

\begin{abstract}
This paper starts from a basic premise: During the last years, there have been multiple corruption cases that affected public administrations credibility, but also the one of the private sectors of the economy. Areas such as urban planning or public contracting have been prolix regarding the occurrence of criminal activities that undermine the proper functioning of the Public Administration and business activity based on ethics and legality. Consequently, it is very important to implement internal complaint

* El artículo se enmarca como parte de mi actividad investigadora: DER 2016-79705-R; GIR Programas de Cumplimiento y Responsabilidad Penal de las Personas Jurídicas USAL; investigador visitante de FLACSO Sede Ecuador; y miembro del grupo de investigación «Políticas públicas, seguridad internacional y gobernanza global» de la Universidad Europea de Madrid. Asimismo, forma parte del Módulo Jean Monnet 611881-EPP-1-2019-1-ES-EPPJMO-MODULE, denominado «Enfoque interdisciplinario sobre desarrollo de competencias cívicas con perspectiva europea» (Eulatafpol).

** Profesor de Derecho Penal en la Universidad de Salamanca, España. Doctor en Derecho Penal por la Universidad de Salamanca.

Código ORCID: 0000-0001-9775-9440. Correo electrónico: jbs@usal.es
\end{abstract}


mechanisms to improve organizations (public and private ones) by prematurely discovering illicit conduct and, in turn, identifying the individuals responsible for such acts. In the same way, for some companies, the verification of the effectiveness of the complaint channels in court contributes to corporate defenses and in achieving exemption from criminal responsibility. Therefore, from a technical perspective, guidelines and recommendations are offered from different regulations point of view to increase the effectiveness of these channels and to reduce the legal uncertainty that occurs in Spain, given the limited drafting of the Penal Code. Likewise, anonymity, paid denunciation and the protection of the complainant against retaliation are addressed.

Key words: Whistleblower, corporate crime, compliance programs, public compliance, prevention, Spain

CONTENIDO: I. INTRODUCCIÓN.- II. ALERTADORES Y CANALES DE DENUNCIA: APROXIMACIÓN CONCEPTUAL Y REFERENCIAS NORMATIVAS.III. LA EXPERIENCIA DE CASTILLA Y LEÓN EN LA PROTECCIÓN DE DENUNCIANTES DENTRO DE LA ESFERA PÚBLICA.- IV. PROPOSICIÓN DE LEY INTEGRAL DE LUCHA CONTRA LA CORRUPCIÓN Y PROTECCIÓN DE LOS DENUNCIANTES IMPULSADA POR EL PARTIDO POLÍTICO CIUDADANOS.- V. DIRECTIVA (UE) 2019/1937, DE 23 DE OCTUBRE DE 2019, RELATIVA A LA PROTECCIÓN DE LAS PERSONAS QUE INFORMEN SOBRE INFRACCIONES DEL DERECHO DE LA UNIÓN.- VI. LEY 10/2010, DE 28 DE ABRIL, DE PREVENCIÓN DEL BLANQUEO DE CAPITALES Y DE LA FINANCIACIÓN DEL TERRORISMO.- VII. LAS NORMAS UNE-ISO Y SU REFERENCIA A LOS CANALES DE DENUNCIA: UNE-ISO 19600 Y UNE.19601.- VIII. CRITERIOS DE EFICACIA DE LOS CANALES DE DENUNCIA.- IX. CONCLUSIONES.

\section{INTRODUCCIÓN}

La irritante corrupción detectada en las más altas instancias de la política y la vida económica de España durante las últimas décadas permite afirmar que determinadas instituciones de la Administración pública deben ser reformadas ante la ineficacia de las mismas para prevenir o detectar conductas indebidas en su seno. Este cambio no será fácil. Tal y como ha señalado Villoria Mendieta (2018), «cambiar instituciones exige cambiar los equilibrios de poder, modificar las asimetrías existentes. No es sencillo que el cambio surja desde los que disfrutan del status quo» (p. 195).

En ese sentido, no cabe ninguna duda de que es imprescindible considerar los tradicionales estudios sobre marcos de integridad y las recientes investigaciones vinculadas al public compliance para reestructurar las instituciones y los procesos que en ella acontecen con el objetivo de lograr un funcionamiento orientado al fiel cumplimiento de la ley y al fomento de la ética en la labor del empleado público (Gutiérrez Pérez, 2018, p. 104). La denuncia es parte de la participación de los ciudadanos 
en la esfera administrativa pública (Pérez Monguió, 2019, p. 92); en consecuencia, la Administración debe ser transparente y accesible.

En España hemos tenido una deficiente regulación nacional, autonómica y local para prevenir conductas delictivas en las Administraciones públicas. Refuerza esta idea el hecho de que apenas el $35 \%$ de los españoles confía en las Comunidades Autónomas y el 49 \% en los Ayuntamientos (Lapuente, 2018, p. 27). Este trabajo analizará, a modo de ejemplo, la norma autonómica de Castilla y León por ser una de las pocas que, dentro de España, ha regulado la cuestión de los denunciantes ${ }^{1}$.

Igualmente, el sector privado ha ofrecido numerosos casos de criminalidad corporativa que han afectado a todo el territorio nacional, especialmente en cuestiones vinculadas a la corrupción urbanística y la contratación pública. Al respecto, la actividad empresarial genera mayores riesgos para los bienes jurídico-penales si en ella no tienen cabida principios éticos y de integridad. Es decir, sin compliance, el management corporativo puede ser defectuoso.

Según la web Casos Aislados, que realiza una exhaustiva contabilización de casos de corrupción en España, hasta abril de 2020 se han podido contabilizar 587 causas, que implican a 3837 personas, entre las que se incluye a un buen número de políticos y empresarios (Casos aislados de una corrupción sistémica, s.f.). La existencia de tan importante número de casos debe hacernos repensar la necesidad de modificar el funcionamiento y la estructura de nuestras instituciones de tal forma que su rediseño minimice el número de infracciones, pues para que tantos casos hayan acontecido, otras tantas oportunidades se han tenido que dar. Para ello, es clave identificar a los responsables, tarea a la que contribuirán los denunciantes internos o whistleblower.

El origen del término whistleblower se le atribuye a Ralph Nader en los años setenta del siglo pasado. Dicho concepto habría nacido para asegurar la defensa de los ciudadanos/consumidores ante el poder creciente de los lobbies. Para Nader, whistleblowing significa:

aquel acto de un hombre o una mujer que, creyendo que el interés público es superior al interés de la organización a la que sirve, toca el silbato que alerta de que la organización está realizando actividades

1 En particular: Ley 11/2016, de 28 de noviembre, de la Agencia de Prevención y Lucha contra el Fraude y la Corrupción de la Comunitat valenciana; Ley 16/2016, de 9 de diciembre, de la Oficina de Prevención y Lucha contra la Corrupción de las Islas Baleares; Ley 5/2017, de 1 de junio, de Integridad y Ética Públicas de la Comunidad Autónoma de Aragón; Ley foral 7/2018, de 17 de mayo, de la Oficina de Buenas Prácticas y Anticorrupción de la Comunidad Foral de Navarra; y Ley 8/2018, de 14 de septiembre, de Transparencia, Buen Gobierno y Grupos de Interés del Principado de Asturias. Para un repaso esquemático y comparativo sobre las distintas normas autonómicas, se recomienda ver Fundación Hay Derecho (s.f.).

PAUTAS Y

RECOMENDACIONES

TÉCNICO-

JURÍDICAS PARA LA

CONFIGURACIÓN

DE UN CANAL

DE DENUNCIAS

EFICAZ EN

ORGANIZACIONES

PÚBLICASY

PRIVADAS. LA

PERSPECTIVA

ESPAÑOLA

TECHNICAL AND

LEGAL GUIDELINES

AND RECOMMEN-

DATIONS FOR

THE CREATION

OF EFFECTIVE

COMPLAINTS

CHANNELS

IN PUBLIC

AND PRIVATE

ORGANIZATIONS.

THE SPANISH

PERSPECTIVE 
corruptas, ilegales, fraudulentas o perjudiciales (citado en Benítez Palma, 2018, p. 14).

En definitiva, la protección de los denunciantes promueve una cultura de responsabilidad e integridad, tanto en las instituciones públicas como en las privadas, y supone un aliento para que los ciudadanos denuncien las conductas irregulares o delictivas en todo tipo de organizaciones (Organización de Cooperación y Desarrollo Económico, 2016, p. 11). Además, el canal de denuncia es parte del ambiente de control de las organizaciones. Por todo ello, ahondaremos en los condicionantes que propician un eficaz canal de denuncias.

Este trabajo parte de la perspectiva público-privada, ya que los canales de denuncia son útiles para ambos sectores y, además, puesto que no se hace distinción en cuanto al funcionamiento de lo público y de lo privado desde la teoría de la organización. Como ha señalado Villoria Mendieta (2019): «el principal factor relacionado con comportamientos burocráticos no es la titularidad pública o privada, sino el tamaño» (p. 160). Esta perspectiva amplia, que abarca incluso a organizaciones sin ánimo de lucro, es la que defiende la Asociación Española de Compliance (ASCOM) (2017, p. 7) en su Libro Blanco sobre la función de compliance.

\section{ALERTADORESYCANALESDEDENUNCIA:APROXIMACIÓN CONCEPTUAL Y REFERENCIAS NORMATIVAS}

En los últimos años han calado dentro del panorama internacional, probablemente por la influencia norteamericana, las virtudes de los canales de denuncia y la necesidad de realizar investigaciones internas para descubrir los delitos en los entes organizados. A la par que se han impulsado figuras como el arrepentido o el confidente frente al tradicional crimen organizado, en las empresas y en las instituciones públicas ha tomado fuerza el concepto de alertador o whistlebower ${ }^{2}$. Vencer el silencio que propician las estructuras organizadas es una necesidad vital para llevar a cabo investigaciones eficientes que terminen en condena. Asimismo, es conveniente saber que la implementación efectiva de un canal de denuncias reduce en promedio los costes de fraudes en un $50 \%$ a 60 \%, según la Association of Certified Fraud Examiners (Puyol Montero, 2017, p. 27).

Siguiendo a Hers (2002), debemos considerar como alertador a aquella persona que revela deliberadamente información sobre actividades no convencionales que supongan un riesgo para la organización por

2 Dentro de la literatura aparece una multitud de nombres para referirse a aquella persona que aporta información sobre un hecho irregular o ilícito. «Delator, «chivato», «soplón», «informante interno» o «alertador» son frecuentes en los textos especializados en la materia. A mi juicio, «alertador» sería el término más pedagógico a promocionar, pues no presenta connotaciones negativas. 
ser ilegales, peligrosas, inmorales, discriminatorias o que incluyen una infracción de alguna otra manera, generalmente realizadas por miembros presentes o antiguos de la organización (p. 243). Este denunciante puede revelar la información hacia el interior de la organización (whistleblower insider) o hacia un tercero externo (whistleblower jumping) (Leo Castela, 2018, p. 658). Además, la revelación ante un tercero externo podría ser frente a autoridades administrativas, judiciales o policiales, ante una entidad externa a la organización que se contrata para la recepción de denuncias (por ejemplo, un despacho de abogados), o bien ante los medios de comunicación. Ello podría dar lugar a un conflicto entre el derecho a la libertad de expresión del denunciante y el derecho de sigilo o reserva propio de su puesto laboral, especialmente si es un funcionario público ${ }^{3}$.

Los estudios apuntan a que cuando un empleado tiene escasa confianza en la organización de la que forma parte, la probabilidad de denunciar se reduce considerablemente (Leo Castela, 2018, p. 659). Por tanto, no debemos observar tan solo la configuración de los canales de denuncia, sino incentivar en sentido amplio y preventivo la promoción de una cultura organizacional honesta y ética, puesto que esto será decisivo para que los empleados se vean motivados a denunciar internamente. El mejor de los canales internos no será suficiente incentivo si el clima laboral de la organización es tóxico y deshonesto. En esta situación, el trabajador se decantará por denunciar ante un organismo externo, pues previsiblemente dará un mejor tratamiento a la información facilitada.

En todo caso, en lo que se quiere incidir es en que la persecución de la corrupción se ha convertido en la actualidad en un tema fundamental,

3 Sobre los límites a la libertad de expresión y la posibilidad de revelar información a los medios de comunicación por parte de funcionarios público, es importante conocer el Caso Guja vs. Moldavia (Estrasburgo, 12 de febrero de 2008, recurso núm. 14277/04). En dicho caso, el Tribunal Europeo de Derechos Humanos (TEDH) abordó, desde la perspectiva del funcionario público, el derecho a la libertad de expresión (art. 10 Convenio de Roma) en asuntos de interés general cuando un funcionario informa públicamente sobre conductas ilícitas de las que ha tenido conocimiento en el ejercicio de sus funciones. EI TEDH ponderó el interés público de la información confidencial difundida, la veracidad de la misma, los daños sufridos a la imagen de la Administración pública, los motivos del funcionario para la difusión de la información y el derecho a la libertad de expresión del funcionario. En concreto, Guja, empleado de la Fiscalía General de la República de Moldavia, había revelado al periódico Jurnal de Chisinău información que afirmaba la injerencia del vicepresidente del Parlamento nacional en un procedimiento penal pendiente. Guja, demandante en esta causa, había actuado de buena fe en el marco de su libertad de expresión, por lo que no podía justificarse el despido que había recibido y que la Fiscalía intentó justificar alegando que el trabajador había incumplido los artículos 1.4 y 4.11 del reglamento interno del servicio de prensa, al revelar información secreta sin haber consultado antes a sus superiores ni a los responsables de comunicación de la Fiscalía General. En esa situación, debía prevalecer el interés general y la autenticidad de la información, más aún cuando el empleado actuó de buena fe (Sibina Tomàs \& Arnal Arasa, 2008, pp. 157-159). Para una revisión jurisprudencial más extensa sobre el derecho a la libertad de expresión, se recomienda: Heinish vs. Alemania (TEDH, sentencia de 21 de julio de 2011, recurso núm. 28274/08), que trata el despido a una funcionaria pública que trabajaba en geriátrico por denunciar irregularidades graves; Bucur y Toma vs. Rumanía (TEDH, sentencia de 8 de enero de 2013, recurso núm. 40238/02), que aborda la libertad de expresión y la divulgación de secretos en el ámbito militar; y Matúz vs. Hungría (TEDH, sentencia de 21 de octubre de 2015, recurso núm. 73571/10), que analiza la libertad de expresión de una periodista húngara de la televisión pública que fue despedida al denunciar en un libro la censura dentro de la empresa en la que trabajaba (Ordóñez Solís, 2017, pp. 51-54).

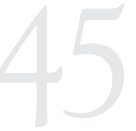

PAUTASY

RECOMENDACIONES

TÉCNICO-

JURÍDICAS PARA LA

CONFIGURACIÓN

DE UN CANAL

DE DENUNCIAS

EFICAZ EN

ORGANIZACIONES

PÚBLICASY

PRIVADAS. LA

PERSPECTIVA

eSPAÑola

TECHNICAL AND

LEGAL GUIDELINES

AND RECOMMEN-

DATIONS FOR

THE CREATION

OF EFFECTIVE

COMPLAINTS

CHANNELS

IN PUBLIC

AND PRIVATE

ORGANIZATIONS.

THE SPANISH

PERSPECTIVE 
tanto en el sector público ${ }^{4}$ como en el privado. La sociedad está exigiendo mayores niveles de transparencia, buena gobernanza y gobierno abierto, lo que incluye una forma ética en la realización de los negocios, y la gestión diligente y sostenible de las administraciones. Reducir la corrupción exige fomentar las denuncias internas en las organizaciones (Pérez Monguió, 2019, p. 84). La denuncia es una herramienta útil para vencer el secretismo, la omertá que rodea a la delincuencia de cuello blanco.

Estamos de acuerdo, por tanto, con Prats Català (2007) cuando señala: «según los entornos institucionales (que incluyen los mecanismos de descubrimiento y represión de la corrupción pero no solo ellos) se incentivarán o desincentivarán más o menos los comportamientos corruptos» (p. 16). En consecuencia, la introducción de sólidos canales de denuncia contribuye de forma directa en la mejora del marco de integridad o, si se prefiere, del sistema de public compliance de la institución; y, por el contrario, su inexistencia o débil implantación favorece el delito. Así, los canales de denuncia ayudan a depurar y «oxigenar» nuestro sistema político, administrativo y económico. Hay que pasar de la crispación y la desafección a la acción (Jiménez Sánchez, 2017, p. 13).

La ausencia de denunciantes en casos de contratación pública supuso en 2017 entre $€ 5800$ y $€ 9600$ millones anuales para el conjunto de la Unión Europea (UE), según la Comisión Europea (2017, p. 13). No hay suficientes estímulos y medios para denunciar la corrupción. El Eurobarómetro sobre la corrupción recoge para 2017 que el $81 \%$ de los empleados «no informaron sobre los casos de corrupción que sufrieron o presenciaron y el $85 \%$ afirmó que los trabajadores muy raramente informan acerca de amenazas o perjuicios por temor a las consecuencias jurídicas y financieras» (Pérez Monguió, 2019, p. 86, nota 14).

El temor a las represalias también ha sido constatado en otros estudios. Según el análisis estadístico realizado por Global Business Ethics Survey en 2016 (entrevistaron a más de 10000 trabajadores públicos y privados de trece Estados), «el $33 \%$ de los trabajadores habían tenido conocimiento de faltas; el $59 \%$ de ellos las denunciaron, y el $36 \%$ de estos sufrieron represalias» (Pérez Monguió, 2019, p. 95). A nivel regional, la Oficina Antifraude de Cataluña detectó en 2018 que dentro de los obstáculos que percibían los ciudadanos para denunciar la corrupción estaba la dificultad para reunir pruebas suficientes (48 \%), el temor a

4 Estudios de la Organización para la Cooperación y el Desarrollo Económicos (OCDE) (2018) señalan que hay una mayor posibilidad de conductas con riesgo legal en las empresas públicas que en las de capital privado, al tener menor capacidad o voluntad que estas para impedir conductas con relevancia penal. 
represalias (30\%), la creencia de que el denunciado no será castigado (27\%) y el desconocimiento sobre los procesos de denuncia (17\%) (p. 97). En consecuencia, será indicio de encontrarnos ante un canal de denuncias eficaz si este reduce significativamente tales condicionantes.

Desde una perspectiva internacional podemos señalar los siguientes instrumentos normativos que han afirmado la utilidad de los canales internos de denuncia:

- Convención de las Naciones Unidas contra la Corrupción, de 31 de octubre de 2003 (art. 33).

- Convenio Penal sobre la Corrupción del Consejo de Europa, de 27 de enero de 1999 (art. 21).

- Convenio Civil sobre la Corrupción del Consejo de Europa, de 4 de noviembre de 1999 (art. 9).

- Reglamento UE 596/2014 del Parlamento Europeo y del Consejo, sobre el abuso de mercado, de 16 de abril de 2014 (art. 32.3).

- Directiva UE 2015/849 del Parlamento Europeo y del Consejo, sobre prevención de la utilización del sistema financiero para el blanqueo de capitales o la financiación del terrorismo, de 20 de mayo de 2015 (art. 61. 3).

- Convención Interamericana contra la Corrupción, de 29 de marzo de 1996 (art. III, 8).

- Convención de la Unión Africana para Prevenir y Combatir la Corrupción, de 12 de julio de 2003 (arts. 5.5-7).

- Protocolo contra la corrupción de la Comunidad de Desarrollo de África Meridional, de 14 de agosto de 2001 (art. 4.1).

Muchos países han legislado estatalmente, desde la perspectiva del derecho nacional, para proteger a los denunciantes por conductas vinculadas a la corrupción, pero no es el caso de España. Se puede mencionar, entre otros:

- Albania: Ley de Denuncia y Protección de Denunciantes (2016).

- Australia: Ley de Divulgación de Interés Público (2013).

- Bélgica: Ley relativa a la notificación de presuntos daños a la integridad dentro de una autoridad administrativa federal por parte de un miembro de su personal (2013).

- Canadá: Ley de Protección de la Divulgación de los Servidores Públicos (2005).

- Corea del Sur: Ley de Protección de los Denunciantes de Interés Público (2011).

PAUTAS Y

RECOMENDACIONES

TÉCNICO-

JURÍDICAS PARA LA

CONFIGURACIÓN

DE UN CANAL

DE DENUNCIAS

EFICAZ EN

ORGANIZACIONES

PÚBLICASY

PRIVADAS. LA

PERSPECTIVA

ESPAÑOLA

TECHNICAL AND

LEGAL GUIDELINES

AND RECOMMEN-

DATIONS FOR

THE CREATION

OF EFFECTIVE

COMPLAINTS

CHANNELS

IN PUBLIC

AND PRIVATE

ORGANIZATIONS

THE SPANISH

PERSPECTIVE 
- Croacia: Ley de Protección de Personas que Denuncian Irregularidades (2019).

- Lituania: Ley de Protección de Denunciantes (2019).

- Malta: Ley de Protección de los Denunciantes (2013).

- Grecia: Ley N 4254 de Medidas para Apoyar y Desarrollar la Economía Griega (2014).

- Moldavia: Ley de Integridad (2017).

- Eslovaquia: Ley sobre determinadas medidas relativas a la denuncia de actividades antisociales (2014).

- Eslovenia: Ley de Integridad y Prevención de la Corrupción (2011).

- Luxemburgo: Ley que Refuerza los Medios para Combatir la Corrupción (2011).

- Francia: Ley de Transparencia, la Lucha contra la Corrupción y la Modernización de la Vida Económica, № 2016-1691 (2016).

- Hungría: Ley CLXIII sobre la Protección de Procedimientos Justos (2009).

- Japón: Ley de Protección de los Denunciantes (2004).

- Países Bajos: Ley del Centro de Denunciantes (2016).

- Nueva Zelanda: Ley de Divulgaciones Protegidas (2000).

- Reino Unido: Ley de Divulgación de Interés Público (1998).

- Estados Unidos: Ley de Protección de Denunciantes (1989).

- Irlanda: Proyecto de Ley de Divulgaciones Protegidas (2013).

- Italia - Ley $\mathrm{N}^{\circ} 190$ para la Prevención y Represión de la Corrupción y la Ilegalidad en la Administración Pública (2012); y Ley $\mathrm{N}^{\circ} 179$ para la protección de los autores de denuncias de delitos o irregularidades de las que tengan conocimiento en el marco de una relación laboral pública o privada (2017).

- Rumania: Ley de Protección del Funcionario Público Denunciante de Violaciones a la Ley (2004).

- Serbia: Ley de Protección de Denunciantes (2014).

- Suecia: Ley de protección especial para los trabajadores contra las represalias por denuncia de irregularidades graves (2016).

En Europa, el Parlamento Europeo ha aprobado en abril de 2019 la Directiva relativa a la protección de las personas que informan exclusivamente sobre infracciones del derecho de la Unión (apartado IV 
de este trabajo). Este es un hito especialmente importante, pues enseña un camino regulatorio a los Estados miembros para que protejan a los denunciantes. En el ámbito nacional, la experiencia española revela que los delatores en casos de corrupción están totalmente desprotegidos jurídicamente y sufren un auténtico calvario judicial y personal. En Estados Unidos, los datos sobre la persecución a los alertadores son tremendamente contundentes y preocupantes. Según un estudio realizado en dicho país con 84 informantes, ha podido concluirse que el $10 \%$ de ellos ha intentado suicidarse, un $60 \%$ ha sido despedido y hasta un $82 \%$ padeció algún tipo de hostigamiento (Bermejo, 2013, p. 65).

Realizado un repaso global sobre las referencias normativas que recogen directrices sobre los denunciantes y los canales de denuncia, abordaremos de forma particular la experiencia de Castilla y León en la protección de los denunciantes dentro del ámbito funcionarial, por ser esta una de las pocas experiencias existentes dentro del territorio nacional.

\section{LA EXPERIENCIA DE CASTILLA Y LEÓN EN LA PROTECCIÓN DE DENUNCIANTES DENTRO DE LA ESFERA PÚBLICA}

La Comunidad Autónoma de Castilla y León ha legislado recientemente (Ley 2/2016, de 11 de noviembre, por la que se regulan las actuaciones para dar curso a las informaciones que reciba la Administración Autonómica sobre hechos relacionados con delitos contra la Administración pública y se establecen las garantías de los informantes) para otorgarle protección a los denunciantes por corrupción. Tal y como se señala en la Exposición de Motivos:

Se debe otorgar protección a quienes faciliten la información, ello mediante la inamovilidad en la relación de servicio y en el desempeño de las funciones, principio rector que proclama la Ley de la Función Pública de Castilla y León como garantía de la independencia en la prestación de servicios, lo cual se articula a través de una serie de medidas de diversa intensidad.

Si bien es cierto que debemos valorar la aparición de normas sobre esta materia como positiva, recordemos que no había una normativa específica al respecto hasta la reciente directiva (Directiva relativa a la protección de las personas que informen sobre infracciones del Derecho de la Unión, 2019), que no lo ha hecho de una manera totalmente recomendable ${ }^{5}$. En palabras de Villoria Mendieta (2018), si bien la normativa de Castilla y León ha regulado de manera específica la figura del denunciante en el ámbito de la función pública, «lo ha hecho

5 Todo parece apuntar que la ley «se va a reformar próximamente para mejorarla y ampliarla dados sus escasos resultados» (De La Nuez Sánchez-Cascado, 2019).

PAUTASY

RECOMENDACIONES TÉCNICO-

JURÍDICAS PARA LA CONFIGURACIÓN

DE UN CANAL

DE DENUNCIAS

EFICAZEN

ORGANIZACIONES

PÚBLICASY

PRIVADAS. LA

PERSPECTIVA

ESPAÑOLA

TECHNICAL AND

LEGAL GUIDELINES

AND RECOMMEN-

DATIONS FOR

THE CREATION

OF EFFECTIVE

COMPLAINTS

CHANNELS

IN PUBLIC

AND PRIVATE

ORGANIZATIONS.

THE SPANISH

PERSPECTIVE 
de tal manera que más amenaza que protege, pues sanciona de forma desproporcionada a quienes denuncien sin pruebas» (pp. 217-218). En particular, la norma de Castilla y León señala en su artículo 3.5 que será falta grave:

La presentación de informaciones infundadas cuando en las actuaciones llevadas a cabo en la información reservada se pruebe de forma manifiesta su falta de fundamento, todo ello sin perjuicio de las consecuencias que establece el ordenamiento jurídico para los supuestos de acusación y denuncia falsas y simulación de delitos tipificados en el capítulo V, del título XX del libro II del Código Penal.

Sin embargo, nada dice la norma castellana sobre qué tipo de calificación merece (falta grave o muy grave) aquella persona de la Administración que rompe la confidencialidad.

Respecto a los sujetos que están habilitados para denunciar los hechos irregulares, la ley menciona en su artículo 1 que podrá hacerlo «el personal» que compone la Administración de Castilla y León respecto de actuaciones que hayan sido realizadas por altos cargos o personal de la Administración General e Institucional de la Comunidad Autónoma, «en el ejercicio de sus cargos o funciones, de las que pudiera derivarse un posible delito contra la Administración Pública de los regulados en el título XIX del Código Penal».

Es muy negativo que el canal solo esté abierto para el personal de la Administración ${ }^{6}$, lo que deja fuera a contratistas, proveedores, personal laboral o cualquier otra persona que pueda tener algún tipo de relación con la Administración (Fernández González, 2019, p. 171). En ese sentido, una mayor apertura agregaría efectividad (Nieto Martín \& García Moreno, 2019, p. 403). Adicionalmente, la participación ciudadana es clave. Estamos de acuerdo, por tanto, con Cerrilloi Martínez (2018) cuando afirma que «la ciudadanía está llamada a tener un papel relevante en la prevención de las malas prácticas en la Administración Pública» (p. 2). Sin embargo, las normas autonómicas de Cataluña y Valencia permiten y diferencian entre el denunciante/funcionario y el denunciante/ciudadano. Por otro lado, la norma castellana, y también la de Aragón, restringen el concepto de denunciante exclusivamente al empleado público de la Comunidad Autónoma en cuestión (Gosálbez Pequeño, 2019, p. 4).

Desde el punto de vista del trámite, en Castilla y León la información aportada por el denunciante será remitida a la Inspección General de Servicios (órgano encargado de investigar la veracidad de la

6 No obstante, las personas que no están habilitadas por la norma de Castilla y León para utilizar el canal pueden denunciar directamente ante el juzgado, la policía o el Ministerio Público. 
información), dando el carácter de reservado a dicha información (se omitirán los datos relativos a la identidad del informante y cuantos pudieran conducir a su identificación). Además, la Inspección General comunicará al procurador del común, en calidad de comisionado de Transparencia, el inicio de la investigación. La Inspección General de Servicios dispondrá de un plazo de dos meses para realizar la investigación y solo en casos excepcionales la investigación podrá extenderse hasta los seis meses, pues el plazo de dos meses resulta adecuado.

Una vez finalizada la investigación por la Inspección General de Servicios, pueden suceder tres cosas:

1. Si los hechos investigados presentan apariencia delictiva, se dará el traslado de la información obtenida y de los indicios recabados al Ministerio Fiscal.

2. Si los hechos investigados fueran constitutivos de una infracción administrativa, la Inspección General de Servicios elaborará un informe explicativo de los hechos, donde se propondrá la apertura de un expediente sancionador que será remitido al órgano de la Administración pública competente en el régimen sancionador.

3. Si los hechos investigados no fueran constitutivos de delito, pero la denuncia hubiera sido realizada de mala fe o sobre hechos infundados, podrá incoarse un expediente sancionador contra el alertador, teniendo la denuncia de mala fe la categoría de falta grave.

Asimismo, si los hechos denunciados no son constitutivos de infracción administrativa ni de delito y, además, la denuncia no hubiera sido realizada de mala fe, entonces se archivarán todas las actuaciones y se dará su traslado al procurador del común — como comisionado de Transparencia - para su conocimiento, notificándose también el archivo de las actuaciones a quien haya proporcionado la información.

En definitiva, podemos valorar de forma positiva la iniciativa de la Junta de Castilla y León de regular normativamente la protección de los denunciantes internos. Se trata de una experiencia normativa demasiado reciente (Benítez Palma, 2018, p. 29) para valorar su efectividad ${ }^{7}$, aunque lo cierto es que dicha norma es muy limitada en algunos aspectos. Por ejemplo, nada dice sobre si es una obligación o potestad de los funcionarios el deber de denuncia. Tampoco se recoge la posibilidad de brindar asesoría jurídica gratuita al potencial denunciante ${ }^{8}$ ni de, una vez ha formulada la denuncia, ofrecerle asistencia psicológica

7 Desde su entrada en vigor hasta septiembre de 2019 se han recibido un total de veinte denuncias en el canal de denuncias (Agencia de Noticias EFE, 2019).

8 Por ejemplo, la Ley 5/2017, de Integridad y Ética Públicas de la Comunidad de Aragón, sí ofrece esta posibilidad.

PAUTASY

RECOMENDACIONES

TÉCNICO-

JURÍDICAS PARA LA

CONFIGURACIÓN

DE UN CANAL

DE DENUNCIAS

EFICAZ EN

ORGANIZACIONES

PÚBLICAS Y

PRIVADAS. LA

PERSPECTIVA

ESPAÑOLA

TECHNICAL AND

LEGAL GUIDELINES

AND RECOMMEN-

DATIONS FOR

THE CREATION

OF EFFECTIVE

COMPLAINTS

CHANNELS

IN PUBLIC

AND PRIVATE

ORGANIZATIONS.

THE SPANISH

PERSPECTIVE 
o un resarcimiento de los daños y perjuicios que haya podido padecer derivados de su situación como denunciante. La norma de Castilla y León deberá ser reformada si quiere adecuar su contenido a las «indicaciones internacionales» (Vestri, 2019, p. 9). Además, Castilla y León tampoco dispone de una institución orientada a la prevención del fraude y la corrupción a modo de agencia u oficina ${ }^{9}$.

Por todo lo expuesto, la Junta de Castilla y León debe ampliar dicha normativa para favorecer, de facto, que se incremente el número de denunciantes internos en las instituciones de la Comunidad ${ }^{10}$, lo que redundará en una mayor eficiencia y calidad de la administración regional. Ello podría vincularse, también, con el derecho a la buena administración. Si no somos capaces de expulsar las irregularidades del sector público, estamos condenados a una democracia e instituciones de mínimos. La calidad de la democracia requiere transversalmente de la función pública, la transparencia material, el control ciudadano permanente (Moretón Toquero, 2017, pp. 204-206), la cultura anticorrupción ${ }^{11}$ y de legalidad ${ }^{12}$.

\section{LA PROPOSICIÓN DE LEY INTEGRAL DE LUCHA CONTRA LA CORRUPCIÓN Y PROTECCIÓN DE LOS DENUNCIANTES IMPULSADA POR EL GRUPO PARLAMENTARIO CIUDADANOS}

España no dispone de una normativa estatal de protección a los denunciantes, pero en el año 2016 el Grupo Parlamentario denominado Ciudadanos presentó una Proposición de Ley Integral de Lucha contra la Corrupción y Protección de los Denunciantes que merece ser comentada.

La Proposición se fundamenta sobre dos pilares claros. Primero, el reconocimiento de derechos a los denunciantes en el ámbito de las

9 Según declaraciones (de agosto de 2020) del vicepresidente de la Junta de Castilla y León, Francisco Igea, la Comunidad tendrá una Agencia de Prevención y Lucha contra el Fraude y la Corrupción en el plazo de un año. Esta entidad será adscrita a las Cortes de Castilla y León. La Agencia tendrá por funciones: prevenir e investigar el uso o el destino irregular de fondos o patrimonio público; garantizar dentro del ámbito local el ejercicio independiente y eficaz de las funciones de fiscalización y control de la legalidad; realizar análisis de riesgos; programar acciones formativas; concienciar sobre los efectos de la corrupción; etc. (Agencia de Noticias ICAL, 8 de agosto de 2020).

10 A fines de julio de 2019, desde el Consejo de Gobierno de la Junta de Castilla y León se señaló que se reformaría la norma de protección de denunciantes de la Comunidad con el fin de detallar las conductas que pueden ser consideradas corrupción e incrementar los derechos de los denunciantes (mayor confidencialidad, incremento del derecho a recibir información sobre la denuncia formulada, asistencia psicológica o psiquiátrica, asesoría legal gratuita, defensa y representación gratuita). Respecto a la posibilidad de incluir la denuncia anónima, no tenemos ninguna información (Agencia de Noticias ICAL, 25 de julio de 2019).

11 Concordamos con Ferré Olivé (2017) cuando afirma que «se debe instaurar una auténtica cultura anticorrupción, que exija honestidad en ciudadanos, empresarios y gobernantes — un complicado cambio ético-y transparencia en el ejercicio de las cuestiones públicas» (p. 489).

12 La cultura de legalidad germina cuando se produce una sincronización entre los distintos órdenes regulatorios: el legal, el moral y el social. Esto no es posible sin realizar esfuerzos teóricos y prácticos, normativos y de concienciación ética (Güemes, 2018, p. 6). 
administraciones públicas desde una perspectiva integral. Segundo, la creación de una Autoridad Independiente de Integridad Pública que garantice la recta e íntegra actuación en el sector público (art. 1) ${ }^{13}$. Según la Proposición, tendrán la condición de denunciantes:

los altos cargos, los funcionarios y el resto del personal al servicio del sector público que revelen información con apariencia suficiente de veracidad sobre hechos que puedan ser constitutivos de delito o infracción administrativa, en particular delitos contra la Administración Pública o contra la Hacienda Pública, o sobre hechos que puedan dar lugar a responsabilidades por alcance (art. 3).

Posteriormente (19 de diciembre de 2017), Ciudadanos presentó una enmienda al texto original, ampliando el concepto de denunciante para incluir:

contratistas y los beneficiarios de las ayudas públicas, en los términos de la Ley 9/2017, de 8 de noviembre, de Contratos del Sector Público y de la Ley 38/2003, de 17 de noviembre, General de Subvenciones, respectivamente, en relación con los hechos que hubiese podido conocer como consecuencia de la adjudicación de los contratos o de las subvenciones percibidas. En el caso de personas jurídicas, la condición será reconocida a las personas físicas que hubiesen prestado servicios al adjudicatario o al beneficiario de la ayuda (Pérez Monguió, 2019, p. 99, nota 51).

En todo caso, interesa resaltar que, según esta proposición, los denunciantes estarán amparados por los mecanismos de protección frente a represalias que ofrece esta ley, siempre y cuando revelen información que tenga apariencia de veracidad y los hechos enunciados puedan ser constitutivos de delito (contra la Administración pública o contra la Hacienda pública) o infracción administrativa. Estos hechos deben ser denunciados «ante cualquier superior jerárquico, autoridad administrativa o judicial, y en particular ante la Autoridad Independiente de Integridad Pública u órgano autonómico competente» (Proposición de Ley Integral de Lucha contra la Corrupción y Protección de los Denunciantes, 2016, art. 4).

Respecto a la denuncia y el denunciante, debemos conocer que:

1. Las denuncias se tramitarán a través de procedimientos que garanticen la confidencialidad, sin perjuicio de lo que establezcan las normas procesales a los efectos si el caso llegara a judicializarse ${ }^{14}$.

13 Italia también optó en 2017 (Legge 30 novembre 2017, n. 179) por la creación de una Autoridad Nacional Anticorrupción para canalizar las denuncias, sin que ello excluya que los denunciantes puedan acudir a la autoridad judicial o contable para comunicar los hechos ilícitos.

14 En otro caso, podría vulnerarse el derecho a la igualdad y la contradicción que tiene el acusado en el marco de un proceso penal. Asimismo, ello afecta al derecho a la tutela judicial efectiva (Constitución española, art. 24). También el Convenio Europeo para la Protección de los Derechos Humanos y de

PAUTAS Y

RECOMENDACIONES

TÉCNICO-

JURÍDICAS PARA LA

CONFIGURACIÓN

DE UN CANAL

DE DENUNCIAS

EFICAZ EN

ORGANIZACIONES

PÚBLICASY

PRIVADAS. LA

PERSPECTIVA

ESPAÑOLA

TECHNICAL AND

LEGAL GUIDELINES

AND RECOMMEN-

DATIONS FOR

THE CREATION

OF EFFECTIVE

COMPLAINTS

CHANNELS

IN PUBLIC

AND PRIVATE

ORGANIZATIONS

THE SPANISH

PERSPECTIVE 
2. Las personas que intervengan en la tramitación de la denuncia deben garantizar el deber de secreto en sus actuaciones.

3. No podrá considerarse que los informadores denunciantes incumplen su deber de sigilo en el cumplimiento de sus funciones por formular denuncia.

4. Eldenunciante tiene derecho a conocer la situación administrativa de la denuncia y ser notificado sobre los avances que se produzcan en el trámite de la misma. Adicionalmente, tiene derecho a que la denuncia finalice a través de una resolución expresa, suficientemente motivada, en los plazos previstos por la presente ley.

5. El denunciante tendrá asesoría jurídica gratuita en relación a la denuncia presentada.

6. El denunciante no podrá sufrir ningún tipo de represalia, perjuicio o menoscabo personal o profesional por haber formulado denuncia.

7. El denunciante tendrá derecho a ser indemnizado por «daños y perjuicios derivados de la responsabilidad patrimonial de la Administración Pública, cuando acredite la existencia de un daño individualizado y determinado económicamente» (Proposición de Ley Integral de Lucha contra la Corrupción y Protección de los Denunciantes, 2016) que sea consecuencia directa de la denuncia presentada en los términos previstos en la Ley 39/2015, de 1 de octubre, de Procedimiento Administrativo Común de las Administraciones Públicas.

8. El denunciante tendrá derecho a dirigirse a la Autoridad Independiente de Integridad Pública a través de un canal confidencial de denuncias. Lamentablemente, la utilización del mismo está reservada para «los altos cargos, los funcionarios y el resto del personal al servicio de la Administración General del Estado y del sector público estatal», quedando fuera del ámbito de aplicación de la ley los ciudadanos.

La Autoridad, en un plazo de quince días desde la recepción de la denuncia, deberá acordar el inicio de un procedimiento de información reservada (constatación de los hechos), que tendrá que ser comunicado al denunciante. En el caso de que los hechos fueran ciertos y tuvieran apariencia criminal, y en consonancia con lo estipulado en el artículo 5.6 de la Proposición, se deberá dar traslado de lo actuado de forma motivada al Ministerio Fiscal.

las Libertades Fundamentales recoge, en su artículo 6.3 D, que el acusado tiene derecho a interrogar a los testigos que declaren contra él. 
En efecto, la Proposición reconoce al denunciante una posición activa durante la tramitación de la denuncia, concediéndole el derecho a tener conocimiento del estado de la denuncia y de las resoluciones adoptadas. Sin embargo, no permite las denuncias anónimas ni aquellas que no puedan ser respaldadas por documentos o informaciones contrastadas (Campos Acuña, 2018, p. 132). Esto entorpece la estimulación de denuncias ya que el anonimato asegura una mayor tranquilidad y, además, porque en muchas ocasiones no existen documentos físicos que acrediten los hechos y tan solo se cuenta con un relato de hechos con mayor o menor verosimilitud.

También desde una perspectiva crítica, Ragués i Vallès (2017) ha señalado que:

la creación de instancias intermedias de recepción de la información e impulso de los procedimientos como la Autoridad Independiente, produce un efecto consistente en aumentar la complejidad de los circuitos por los que fluirán las denuncias hasta llegar a quienes realmente tienen capacidad de investigar, acusar y sancionar.

Asimismo, tiene razón Raguési Vallès (2017) al señalar que la Proposición olvida que, conforme a la legislación actual, «los funcionarios públicos no sólo tienen ya la posibilidad de denunciar, sino el auténtico deber jurídico ${ }^{15}$ de hacerlo en aquellos delitos de los que tengan conocimiento» (pp. 4-5).

\section{DIRECTIVA (UE) 2019/1937, DE 23 DE OCTUBRE DE 2019, RELATIVA A LA PROTECCIÓN DE LAS PERSONAS QUE INFORMEN SOBRE INFRACCIONES DEL DERECHO DE LA UNIÓN}

PAUTASY

RECOMENDACIONES

TÉCNICO-

JURÍDICAS PARA LA

CONFIGURACIÓN

DE UN CANAL

DE DENUNCIAS

EFICAZ EN

ORGANIZACIONES

PÚBLICASY

PRIVADAS. LA

PERSPECTIVA

eSPAÑola

TECHNICAL AND

LEGAL GUIDELINES

AND RECOMMEN-

DATIONS FOR

THE CREATION

OF EFFECTIVE

COMPLAINTS

CHANNELS

IN PUBLIC

AND PRIVATE

ORGANIZATIONS.

THE SPANISH

PERSPECTIVE

La Directiva (UE) 2019/1937, relativa a la protección de las personas que informen sobre infracciones del Derecho de la Unión, tiene por objetivo constituir un marco regulatorio uniforme para proteger los intereses de la Unión Europea, incentivando las denuncias de alertadores a través de canales de denuncia implementados en organizaciones públicas y privadas. Las Administraciones públicas del Estado (nacionales, regionales, provinciales y locales —de poblaciones con más de 10000 habitantes o que cuenten con al menos cincuenta empleados-) deberán implementar canales internos de denuncia (Nieto Martín \& García Moreno, 2019, p. 394). Estos canales también serán obligatorios para entidades privadas que tengan cincuenta trabajadores o más.

Antes que nada, debe quedar claro que la regulación no obliga a denunciar a los empleados del sector público y privado, sino que les otorga esa

15 Artículo 262 de la Ley de Enjuiciamiento Criminal. 
potestad. Asimismo, la Directiva incide en que los denunciantes dispongan de asesoría completa, independiente, gratuita y fácilmente accesible sobre el procedimiento de denuncia y los derechos que tienen como denunciantes, como el apoyo psicológico y la asistencia jurídica gratuita recogida en la Directiva 2016/1919, relativa «a la asistencia jurídica gratuita en los procesos penales y en el procedimiento de orden europea de detención, y en los procesos civiles transfronterizos», de acuerdo con la Directiva 2008/52/CE (Lozano Cutanda, 2020, p. 8). Para efectos de la protección de la Directiva, el motivo o interés por el que el informante denuncie es irrelevante, lo importante es que ofrezca una información con motivos razonables para creer que sea cierta ${ }^{16}$. En este caso, se entenderá que hay buena fe, aunque finalmente la información fuera incorrecta (2020, p. 4).

La Directiva (UE) 2019/1937 ha entrado en vigor el 16 de diciembre de 2019, estableciendo un plazo de trasposición de dos años desde su promulgación para que los distintos Estados la adopten. Sin embargo, hay un plazo especial para la implementación de estos canales de denuncia en entidades privadas que tengan entre cincuenta ${ }^{17}$ y 249 trabajadores, que se prorroga hasta el 17 de diciembre de 2023.

Para la Directiva (UE) 2019/1937, las infracciones del derecho de la Unión que son objeto de interés particular vienen enumeradas en su artículo 2, incluyendo:

Contratación pública; servicios, productos y mercados financieros y prevención del blanqueo capitales y financiación del terrorismo; seguridad de los productos; seguridad del transporte; protección del medio ambiente; protección frente a las radiaciones y seguridad nuclear; seguridad de los alimentos y los piensos, sanidad animal y bienestar de los animales; salud pública; protección de los consumidores; protección de la intimidad y de los datos personales, y seguridad de las redes y los sistemas de información; intereses financieros de la Unión Europea y, por último, mercado interior.

A los efectos de la temática que abarca este trabajo, la Directiva recoge (art. 3) tres canales de denuncia distintos (internos, externos y revelaciones públicas) por los que el denunciante es totalmente libre de optar (Wolters Kluwers, s.f., p. 7), si bien es cierto que es preferible como buena práctica empresarial que la denuncia se resuelva a nivel interno (Directiva (UE) 2019/1937, art. 7; Wolters Kluwers, s.f., p. 7). Estos tres tipos de canales tienen en común una serie de aspectos, como el deber de confidencialidad

16 El Reino Unido también optó en 2013 por retirar de su legislación sobre denunciantes el requisito de la buena fe. A nivel práctico, este suponía un obstáculo para estimular las denuncias y brindar una protección efectiva (Bachmaier Winter, 2019, p. 6).

17 Este límite no es aplicable a organizaciones que se dediquen a servicios, productos y mercados financieros, y prevención del blanqueo de capitales y la financiación del terrorismo; o a seguridad del transporte y medioambiente. 
(Directiva (UE) 2019/1937, art. 16), el tratamiento responsable de los datos personales (art. 17) y la elaboración de un registro con todas las denuncias recibidas (art. 18).

Asimismo, la Directiva ofrece unas pautas concretas sobre la configuración y funcionalidad de los canales de denuncias, señalando que estos deben incorporar: a) mecanismos que garanticen la confidencialidad del denunciante y un uso restringido de la gestión del canal para garantizar la identidad no solo del denunciante, sino de cualquier tercero que sea mencionado en la denuncia; b) un plazo de siete días para formalizar el acuse de recibo de la denuncia que se ha hecho llegar a la organización; c) una clara designación de la persona o del departamento que será el encargado de tramitar la denuncia y mantenerse en contacto con el denunciante; d) un tratamiento responsable en cuanto a lo que establezca el derecho nacional en materia de denuncias anónimas; e) un plazo para estudiar, tramitar y contestar al denunciante que no sea superior a tres meses a contar desde el acuse de recibo; f) políticas claras sobre las posibilidades que tienen los denunciantes para formular denuncias externas ante las autoridades competentes de conformidad con el artículo 10 de la Directiva y, en su caso, ante las instituciones, órganos y organismos de la Unión; y g) la posibilidad de formalizar la denuncia a través de un formato digital o en soporte físico escrito, a través del teléfono o mediante reuniones presenciales (Bachmaier Winter \& Martínez Santos, 2019, p. 544).

Como no podía ser de otra manera, la Directiva prohíbe las represalias contra los denunciantes, enumerando las siguientes: suspensión, despido, destitución, degradación o limitación de ascensos; modificación de su puesto de trabajo; imposición de medidas disciplinarias; discriminación; trato desfavorable o injusto; y los daños a la reputación (art. 19). También se prohíbe la inclusión del denunciante en listas negras que le impidan trabajar dentro de un determinado sector (blacklisting) (Bachmaier Winter, 2019, p. 6). En consecuencia, ante la imposición de sanciones al denunciante que pudieran constituir algún tipo de represalia, la Directiva invierte la carga de la prueba en procedimientos de naturaleza administrativa, civil y laboral (Lozano Cutanda, 2020, p. 9).

Es apropiado que la propia Directiva determine la protección que tienen los denunciantes ante posibles responsabilidades legales que sufran por haber relevado información de forma pública, teniendo motivos razonables para hacerlo. Ante esta situación, la Directiva los blindará jurídicamente para que no incurran en responsabilidad por haber infringido algún tipo de limitación o restricción de difusión pública.

PAUTAS Y

RECOMENDACIONES

TÉCNICO-

JURÍDICAS PARA LA

CONFIGURACIÓN

DE UN CANAL

DE DENUNCIAS

EFICAZEN

ORGANIZACIONES

PÚBLICASY

PRIVADAS. LA

PERSPECTIVA

ESPAÑOLA

TECHNICAL AND

LEGAL GUIDELINES

AND RECOMMEN-

DATIONS FOR

THE CREATION

OF EFFECTIVE

COMPLAINTS

CHANNELS

IN PUBLIC

AND PRIVATE

ORGANIZATIONS.

THE SPANISH

PERSPECTIVE 


\section{LEY 10/2010, DE 28 DE ABRIL, DE PREVENCIÓN DEL BLANQUEO DE CAPITALES Y DE LA FINANCIACIÓN DEL TERRORISMO}

En España, la Ley 10/2010, de 28 de abril, de Prevención del Blanqueo de Capitales y la Financiación del Terrorismo, ha sido modificada a través del Real Decreto-ley 11/2018, de 31 de agosto, a los efectos de transponer al ordenamiento español la Directiva (UE) 2015/849, del Parlamento Europeo y del Consejo, de 20 de mayo de 2015, relativa a la prevención de la utilización del sistema financiero para el blanqueo de capitales o para la financiación del terrorismo. Esta norma sectorial es realmente interesante desde una perspectiva de compliance, puesto que el artículo 26 bis recoge los procedimientos internos con los que deben contar los sujetos obligados para comunicar potenciales incumplimientos que están sucediendo en la organización.

En particular, el artículo 26 bis de la Ley 10/2010 señala en su apartado primero que los sujetos obligados deben establecer:

procedimientos internos para que sus empleados, directivos o agentes puedan comunicar, incluso anónimamente ${ }^{18}$, información relevante sobre posibles incumplimientos de esta ley, su normativa de desarrollo o las políticas y procedimientos implantados para darles cumplimiento, cometidos en el seno del sujeto obligado.

Asimismo, el apartado tercero impone a los sujetos obligados la necesidad de adoptar medidas «que garanticen que los empleados, directivos o agentes que informen de las infracciones cometidas en la entidad sean protegidos frente a represalias, amenazas, acciones hostiles, discriminaciones y cualquier otro tipo de trato injusto».

Igualmente, es importante resaltar que la ley recoge que es preceptivo para los sujetos obligados realizar cursos de formación con la finalidad de que todos los empleados conozcan las exigencias que se derivan de esta regulación (art. 29). En consecuencia, podemos afirmar que los empleados deberán ser instruidos sobre el funcionamiento y la finalidad del canal de denuncias. Además, la ley recoge que la no implementación de un canal de denuncias en aquellos sujetos obligados (art. 2.1) supondrá la consideración de una infracción leve, con una sanción de hasta $€ 60000$ (art. 53. L) (Wolters Kluwers, s.f., pp. 5-6).

18 El proyecto de ley señalaba que los canales de denuncia serían anónimos en todo caso. Finalmente, el texto permite el anonimato y la confidencialidad. 
VII. LAS NORMAS UNE-ISO Y SU REFERENCIA A LOS CANALES DE DENUNCIA: UNE-ISO 19600 Y UNE 19601 Las normas UNE-ISO son excelentes referentes regulatorios para observar cuáles son los estándares técnicos que se consideran idóneos para diseñar, implementar, ejecutar y revisar un sistema de gestión de compliance en sentido amplio (UNE-ISO 19600) o, en particular, un sistema certificable de gestión de compliance penal (UNE 19601). En lo que interesa a este trabajo, detallaremos qué pautas ofrecen dichos estándares en lo que concierne a los canales de denuncia.

En el ámbito privado, la norma UNE-ISO 19600, Sistemas de Gestión de Compliance (versión de abril de 2015), ha ofrecido una serie de directrices y recomendaciones útiles que determinan el estándar internacional de cumplimiento normativo. Así, respecto a los canales de denuncia, la norma ofrece interesantes consideraciones.

Las organizaciones deben disponer de procesos claros para asegurar que los incumplimientos que se producen en la organización sean reportados de forma puntual a la alta dirección y sometidos a la función de cumplimiento de la organización. Al mismo tiempo, es necesario que se encuentre debidamente descrito en el protocolo de la organización ante quién, cómo y cuándo se deben reportar los incumplimientos, y qué posibilidades hay de reporte interno y externo. Es importante crear un entorno organizacional que incentive los reportes de incumplimientos y que proteja a los denunciantes (UNE-ISO 19600, apartado 7.3.2.2.D).

Asimismo, el canal de denuncias permitirá no solo recoger información sobre incumplimientos desde los integrantes de la organización, sino que también contiene la posibilidad de que sean terceras partes las que informen sobre malas prácticas reales o sospechosas, o sobre la violación de alguna de las obligaciones de compliance de la organización. En cualquier caso, tanto integrantes de la organización como terceros podrán informar de forma confidencial ${ }^{19} \mathrm{y}$ sin represalias (UNE-ISO 19600, apartado 10.1.2).

Finalmente, el estándar técnico establece la necesidad de elaborar informes de cumplimiento donde se enumeren y detallen los incumplimientos detectados, así como su análisis subsiguiente (UNEISO 19600, apartado 9.1.8.D).

Ya en el ámbito estrictamente penal, nos encontramos con la norma UNE 19601, sobre Sistemas de gestión de compliance penal (versión de mayo de 2017). Se trata de un estándar de cumplimiento normativo en materia penal que detalla los requerimientos exigibles para que las organizaciones estén debidamente gestionadas en cuanto a la mitigación

19 El apartado 5.3.2.2.D de dicha norma permite que la organización implemente canales de denuncia incluso anónimos.

Derecho PUCP, № 85, 2020 / e-ISSN: 2305-2546

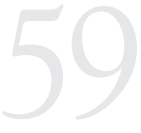

PAUTASY

RECOMENDACIONES

TÉCNICO-

JURÍDICAS PARA LA

CONFIGURACIÓN

DE UN CANAL

DE DENUNCIAS

EFICAZ EN

oRgANIZACIONES

PÚBLICASY

PRIVADAS. LA

PERSPECTIVA

ESPAÑOLA

TECHNICAL AND

LEGAL GUIDELINES

AND RECOMMEN-

DATIONS FOR

THE CREATION

OF EFFECTIVE

COMPLAINTS

CHANNELS

IN PUBLIC

AND PRIVATE

ORGANIZATIONS.

THE SPANISH

PERSPECTIVE 
del riesgo penal. Así, a través del seguimiento de este estándar, será más fácil que las organizaciones acrediten en sede judicial que han sido diligentes en su gestión corporativa, satisfaciendo las exigencias descritas en el artículo 31 bis, apartado 5, del Código Penal español, en lo relativo a los elementos del programa de cumplimento. No debemos olvidar que el Código Penal es muy parco al mencionar las características del canal de denuncias, señalando en el artículo 31 bis, apartado 5, numeral 4, tan solo que «Impondrán la obligación de informar de posibles riesgos e incumplimientos al organismo encargado de vigilar el funcionamiento y observancia del modelo de prevención».

Respecto a los canales de denuncia, la norma UNE 19.601 dispone que las organizaciones deben facilitar canales de comunicación para que tanto los integrantes de la misma como terceros puedan comunicar de buena fe, y sobre la base de indicios razonables, aquellas circunstancias que constituyan o puedan constituir un riesgo penal para la organización (apartado 8.7), asegurando que todas las comunicaciones sean analizadas. Para ello, se dotará de recursos, autonomía e independencia al órgano encargado de realizar las investigaciones pertinentes. Asimismo, la organización siempre garantizará los derechos de los denunciantes y denunciados, adoptando medidas adecuadas y proporcionales (apartado 8.8).

Los canales de comunicación deben garantizar la confidencialidad o el anonimato ${ }^{20}$ de los denunciantes y, en todo momento, la organización debe proteger a los denunciantes de buena fe, sobre la base de indicios razonables, de todo tipo de represalias que pudieran padecer.

Los protocolos y procedimientos de la organización deben garantizar que los informantes conocen la existencia y funcionamiento de los canales de denuncia. Estos canales serán fomentados desde el seno de la organización para un mayor y mejor uso de los mismos, lo que incluye resolver integralmente dudas e inquietudes sobre su utilización.

\section{VIII.CRITERIOS DE EFICACIA DE LOS CANALES DE DENUNCIA}

El logro de la eficacia en un canal de denuncias responde a intereses de distinta naturaleza, pero todos valiosos. Desde el punto de vista del sector privado (empresas, partidos políticos, sindicatos y ONG), el diseño, implementación, ejecución y revisión de un canal de denuncias adecuado contribuye, junto con otros factores, al convencimiento en sede judicial de que el programa de cumplimiento normativo es

20 También la norma UNE 19.602, Sistemas de gestión de compliance tributario (versión de febrero de 2019), permite la denuncia anónima (apartado 8.7.B). 
idóneo y eficaz ${ }^{21}$. Ello es muy importante para las defensas legales de las personas jurídicas, pues podrán evitar la responsabilidad penal del ente. Por otro lado, desde una visión criminológica y de justicia, los canales de denuncia permiten detectar infracciones para ser corregidas y, a su vez, facilitan la localización de individuos criminales que pervierten el funcionamiento de las organizaciones de las que forman parte. Por tanto, desde su localización y sanción, se pretende lograr un funcionamiento más ético y legal en las organizaciones a través de la depuración de responsabilidades. Todo ello, además, revierte en una mejor percepción ciudadana sobre nuestras organizaciones.

De forma esquemática, la eficacia del canal de denuncias ha sido abordada por Pérez Treviño (2018). Para este, son ocho aspectos los que deben examinarse a la hora de evaluar la eficacia: a) el compromiso y respaldo de la alta dirección con el canal; b) el grado de información previa que se facilita a los empleados sobre el uso del canal; c) la accesibilidad del canal; d) la configuración proporcional del canal de denuncias; e) el sistema de documentación del mismo; f) el nivel de independencia del órgano encargado de gestionar las denuncias; g) la completitud del sistema de sanciones e infracciones que ampara el canal; y h) la protección que se le ofrece al denunciante de buena de fe (p. 292).

Teniendo en cuenta la importancia de estos canales es conveniente detallar algunas cuestiones que han sido expuestas por la doctrina y que deben ser atendidas para que estos canales sean considerados eficaces. Como es lógico, el carácter privado o público de la organización en la que se implemente un canal de denuncias conlleva matizaciones y particularidades, pero en lo que sigue se darán pautas que pueden ser entendidas de forma global.

1. La introducción del canal de denuncias en la organización y del procedimiento de investigaciones internas debe ser negociada con los representantes de los trabajadores, en atención al artículo 64 del Estatuto de los Trabajadores.

2. Resulta imprescindible asegurar que la recogida de datos durante la recepción de la denuncia y la realización de la investigación sea lo más amplia posible, siendo recopilada por personas que tengan garantizadalaindependencia, imparcialidad yobjetividad (Velasco Núñez \& Saura Alberdi, 2016, p. 42). La recepción de denuncias y la realización de investigaciones internas debe caracterizarse por la existencia de un procedimiento justo y objetivo (Goñi

21 Artículo 31 bis. $2.2^{\circ}$ del Código Penal: «Si el delito fuere cometido por las personas indicadas en la letra a) del apartado anterior, la persona jurídica quedará exenta de responsabilidad si se cumplen las siguientes condiciones: 1. - el órgano de administración ha adoptado y ejecutado con eficacia, antes de la comisión del delito, modelos de organización y gestión que incluyen las medidas de vigilancia y control idóneas para prevenir delitos de la misma naturaleza o para reducir de forma significativa el riesgo de su comisión» (énfasis añadido).

PAUTAS Y

RECOMENDACIONES

TÉCNICO-

JURÍDICAS PARA LA

CONFIGURACIÓN

DE UN CANAL

DE DENUNCIAS

EFICAZ EN

ORGANIZACIONES

PÚBLICASY

PRIVADAS. LA

PERSPECTIVA

ESPAÑOLA

TECHNICAL AND

LEGAL GUIDELINES

AND RECOMMEN-

DATIONS FOR

THE CREATION

OF EFFECTIVE

COMPLAINTS

CHANNELS

IN PUBLIC

AND PRIVATE

ORGANIZATIONS.

THE SPANISH

PERSPECTIVE 
Sein, 2011, p. 331). A su vez, las personas encargadas de realizar las investigaciones internas deben ser especialmente escrupulosas para adoptar medidas de seguridad y protección que garanticen la no revelación de la identidad del denunciante ni de ningún otro dato relevante. Asimismo, deben ser personas con obligaciones reforzadas de confidencialidad (Lousada Arochena, 2019, p. 35).

3. La implementación del canal debe ir acompañada de una regulación explicativa del funcionamiento del mismo, así como de las garantías que se ofrecen al denunciante para salvaguardar la confidencialidad o el anonimato. Además, la capacitación de los empleados a través de talleres y jornadas resulta oportuna y necesaria.

4. El canal de denuncias debe ser respaldado por la alta dirección y alcanzar a todas las estructuras y niveles de la organización. El uso del canal debe ser divulgado ampliamente entre todos los miembros de la entidad (Velasco Núñez \& Saura Alberdi, 2016, p. 42).

5. Un canal de denuncias que pretende ser efectivo debe proteger al denunciante frente a las represalias (Balmaceda Hoyos et al., 2019, p. 182). La guía del Departamento de Justicia de los Estados Unidos para la evaluación de la eficacia del programa de cumplimiento también incide en la necesidad de que la empresa impulse proactivamente un ambiente laboral en el que los empleados no tengan temor a denunciar confidencial o anónimamente (U.S. Department of Justice Criminal Division, 2020, p. 6).

La Organización de Cooperación y Desarrollo Económico (OCDE) (2019) asevera la necesaria protección jurídica y práctica (p. 35) que merecen los alertadores ante tratamientos injustificados (represalias visibles o encubiertas). En ese sentido, es importante invertir la carga de la prueba en favor del alertador cuando el empleador despida al denunciante alegando cualquier motivo, si en el fondo lo que se esconde es una represalia contra el trabajador (Amoedo, 2017, p. 7). Además de incluir la evitación del despido, debemos considerar necesaria la asistencia jurídica gratuita y la «protección en los procesos judiciales, especialmente mediante una exención de la responsabilidad por la revelación de información» (Del Rosal Blasco, 2018, p. 297).

Respecto al acoso (represalias) en el ámbito laboral, cabe citar que la Constitución española, en su artículo 15, recoge el derecho a no sufrir un trato degradante. Igualmente, el Código Penal persigue aquellas situaciones en las que el sujeto activo: 
infligiera a otra persona un trato degradante, menoscabando gravemente su integridad moral, será castigado con la pena de prisión de seis meses a dos años. Con la misma pena serán castigados los que, en el ámbito de cualquier relación laboral o funcionarial y prevaliéndose de su relación de superioridad, realicen contra otro de forma reiterada actos hostiles o humillantes que, sin llegar a constituir trato degradante, supongan grave acoso contra la víctima (art. 173.1).

Como apunte jurisprudencial, debemos señalar que la primera sentencia del Tribunal Supremo español por acoso laboral en las Administraciones públicas data del 23 de julio de 2001 (RJ 2001, 8027). En dicha sentencia se constataba que el Ayuntamiento de Coria había trasladado a un funcionario a un puesto nuevo sin atribuirle funciones y, además, lo ubicaba en el sótano del edificio para que no dispusiera de ventilación ni luz natural. En consecuencia, el Tribunal entendió que había acoso ${ }^{22}$ contra el funcionario y, de este modo, se vulneraba su derecho a la integridad moral (Del Val, 2019).

6. El sistema de denuncias interno debe prever aquellas situaciones en las que el mismo no funcione correctamente. Por ejemplo, si la denuncia no se tramita en un tiempo adecuado, el alertador debe conocer si puede denunciar directamente ante otros organismos.

7. El sistema de denuncias debe aclarar si denunciar es una obligación para los trabajadores o una potestad. En todo caso, la obligación o potestad debe estar acorde con el contrato laboral y con los derechos que le amparan en virtud del Estatuto de los Trabajadores y/o los convenios sectoriales de los que sean parte. Si el programa de cumplimiento pretende ser eficaz, deberá ser obligatorio. En esa línea, el artículo 31 bis CP, apartado $5.4^{\circ}$, afirma que el programa cumplimento debe imponer «la obligación de informar» (Bachmaier Winter \& Martínez Santos, 2019, p. 526).

En las Administraciones públicas, los principios de buen gobierno recogidos en el artículo 26.2.B.3o de la Ley 19/2013, de 9 de diciembre, de transparencia, acceso a la información pública y buen gobierno, establecen que los sujetos comprendidos en el ámbito de aplicación de este título (art. 2) «Pondrán en

22 La existencia de un delito de acoso laboral requiere de la constatación de una serie de elementos. Tal y como ha señalado García San Martín (2020), se exige: «a) realizar contra otro actos hostiles o humillantes, sin llegar a constituir trato degradante; b) que tales actos sean realizados de forma reiterada; c) que se ejecuten en el ámbito de cualquier relación laboral o funcionarial; d) que el sujeto activo se prevalga de su relación de superioridad; e) que tales actos tengan la caracterización de graves» (p. 208)

PAUTASY

RECOMENDACIONES

TÉCNICO-

JURÍDICAS PARA LA

CONFIGURACIÓN

DE UN CANAL

DE DENUNCIAS

EFICAZEN

ORGANIZACIONES

PÚBLICAS Y

PRIVADAS. LA

PERSPECTIVA

ESPAÑOLA

TECHNICAL AND

LEGAL GUIDELINES

AND RECOMMEN-

DATIONS FOR

THE CREATION

OF EFFECTIVE

COMPLAINTS

CHANNELS

IN PUBLIC

AND PRIVATE

ORGANIZATIONS

THE SPANISH

PERSPECTIVE 
conocimiento de los órganos competentes cualquier actuación irregular de la cual tengan conocimiento» (art. 26).

8. Las denuncias de mala fe deben ser sancionadas en todo caso, pues de otro modo las denuncias internas pueden servir de medio para la difamación y, además, enturbian el clima laboral.

9. El funcionamiento del canal de denuncias interno y el procedimiento para la regulación de la investigación interna debe estar redactado de forma escrita, dando respuesta a las interrogantes más habituales:

- Legitimación: iquién puede denunciar? A menor número de sujetos legitimados para denunciar, menor posibilidad de realizar un diagnóstico adecuado del riesgo y menores posibilidades de recibir denuncias. Por ello, la apertura del canal a los stakeholders agregará eficacia al mismo.

En todo caso, es importante señalar que el número de denuncias en la organización no solo dependerá de los sujetos legitimados para su utilización, sino también de los potenciales riesgos de la entidad y de la cantidad y calidad de los controles implementados. Para Antón Teixido (2019), «si los riesgos han sido debidamente identificados y se han establecido los controles adecuados, el riesgo de denuncia disminuye considerablemente» (p. 352).

- Gestión del canal: iserá interno el canal o externo? Desde el punto de vista de la eficacia, lo más idóneo será que el canal de denuncias tenga participación interna y externa, a modo de contrapeso. La externalización de la recepción de las denuncias tranquiliza al denunciante en lo relativo a su identidad y, a su vez, blinda la información (correos electrónicos, informes, copias de seguridad, etc.) a través de un abogado externo pues, a diferencia del abogado in-house, este está amparado por el secreto profesional (World Compliance Association, 2019, p. 115). Además, esta solución evidencia de forma más visible el esfuerzo realizado en independencia y credibilidad (p. 111).

Dentro de la participación externa en el proceso de investigación será posible y quizá recomendable (Jorge Gili, 2019, p. 298), dependiendo de la naturaleza del caso, contar con la participación de un detective privado. Es función de estos, según el artículo 48.1 de la Ley 5/2014, de Seguridad Privada:

la realización de las averiguaciones que resulten necesarias para la obtención y aportación, por cuenta de terceros legitimados, 
de información y pruebas sobre conductas o hechos privados relacionados con los siguientes aspectos: a) Los relativos al ámbito económico, laboral, mercantil, financiero y, en general, a la vida personal, familiar o social [...].

Dentro del ámbito de la Administración pública, también se plantea la necesidad de segmentación de funciones para garantizar la independencia y objetividad. Como han señalado Nieto Martín \& García Moreno (2018):

El órgano encargado de la recepción de la denuncia debe contar con el máximo grado de independencia orgánica y funcional. El Inspector de Servicios o el Interventor General pueden cumplir con estos requerimientos. El órgano encargado de la recepción de las denuncias no será el mismo que se encargue de la investigación de los hechos (p. 43).

En definitiva, segregar funciones es importante a la hora de incrementar la eficacia de los mecanismos de prevención para evitar fallas y situaciones de conflicto de intereses (Organización de Cooperación y Desarrollo Económico, 2019, p. 28). En particular, es necesario separar la función de recepción de denuncias de la realización de la investigación interna. También es conveniente que la recepción de la denuncia interna llegue al menos a dos personas distintas; de esta forma, se dificulta que las denuncias se escondan o destruyan prematuramente por deseos espurios (Asociación Española de Compliance, 2016, p. 294).

- Canales de comunicación: idesde dónde puede formularse la denuncia? Un mayor número de medios (personalmente, buzón, web, email, teléfono, etc.) permitidos facilitará al empleado animarse a denunciar, pues podrá escoger el que mayores garantías o tranquilidad le genere.

- Ámbito material: iqué se puede denunciar? Una práctica recomendable es que el canal de denuncias ofrezca un formulario estandarizado (World Compliance Association, 2019, p. 111), de tal forma que se facilite al alertador prestar un relato de los hechos ordenado en el que no se olvide la aportación de determinados datos fundamentales para dar viabilidad a la denuncia. En otro caso, la información del aportante puede ser demasiado breve o incompleta, lo que dificultará el cribado de las denuncias. Asimismo, será una virtud del canal de denuncias que permita adjuntar documentos (PDF, Word, Excel, etc.), fotografías o videos.

PAUTASY

RECOMENDACIONES TÉCNICO-

JURÍDICAS PARA LA CONFIGURACIÓN

DE UN CANAL

DE DENUNCIAS

EFICAZEN

ORGANIZACIONES

PÚBLICASY

PRIVADAS. LA

PERSPECTIVA

ESPAÑOLA

TECHNICAL AND

LEGAL GUIDELINES

AND RECOMMEN-

DATIONS FOR

THE CREATION

OF EFFECTIVE

COMPLAINTS

CHANNELS

IN PUBLIC

AND PRIVATE

ORGANIZATIONS

THE SPANISH

PERSPECTIVE 
- Protección de la identidad del denunciante: iel canal es confidencial o anónimo? Como bien ha señalado Pérez Treviño (2018), el anonimato tendría algunas ventajas frente a la confidencialidad. Este mecanismo «garantizará que no se puedan tomar, por parte de la organización, medidas de represalias, así como que los whistleblowers no aparezcan como "chivatos" ante sus compañeros» (p. 294). Si bien es cierto que el anonimato incentiva la denuncia por la tranquilidad que ofrece al alertador, también es posible que promocione la denuncia de mala $\mathrm{fe}^{23}$, lo que no debería ser un gran problema si se establece un buen sistema de depuración o cribado de denuncias.

Desde el punto de vista de la Administración pública, para Nieto Martín \& García Moreno (2018) la denuncia anónima estará justificada en la Administración pública cuando:

esté suficientemente fundamentada, o cuando el bien jurídico en juego merezca especial protección (lesione o ponga en peligro la vida, la integridad física y moral, y a la libertad sexual). Igualmente las denuncias anónimas son proporcionadas cuando se refieran a altos cargos (p. 45).

- Protección de datos personales: icumple el canal de denuncias la ley de protección de datos personales? Hay que verificar si el canal de denuncias respeta el artículo 24 de la Ley Orgánica 3/2018, de 5 de diciembre, de Protección de Datos Personales y garantía de los derechos digitales, pues dicho artículo señala que los datos personales del canal de denuncias deben conservarse por el tiempo «imprescindible» para decidir si se abre un proceso de investigación interno o si, por el contrario, se descarta abrirlo al no presentar apariencia de irregularidad o delito los hechos descritos, en cuyo caso se debe conservar la información, anonimizando los datos del denunciante. El artículo 24.4 señala:

En todo caso, transcurridos tres meses desde la introducción de los datos, deberá procederse a su supresión del sistema de denuncias, salvo que la finalidad de la conservación sea dejar evidencia del funcionamiento del modelo de prevención de la comisión de delitos por la persona jurídica.

Debemos tener presente el plazo de prescripción de los delitos imputables a las personas jurídicas, pues hasta ese punto la

23 Aquellas denuncia falsas realizadas de mala fe que tengan el carácter confidencial (pues son las únicas que identifican al alertador) pueden constituir un delito de injurias o calumnias $y$, a su vez, dar lugar a responsabilidad civil como consecuencia de la lesión del derecho al honor del denunciado (García Moreno, 2015, p. 224). 
entidad puede ser llevada ante los tribunales. Por consiguiente, la persona jurídica investigada deberá demostrar en ese instante evidencias de la eficacia del canal de denuncias y de las investigaciones internas realizadas, por lo que los datos o pesquisas desarrolladas no podrán eliminarse hasta el momento de prescripción del delito.

- iEl canal de denuncias genera evidencias? Un canal de denuncias informatizado permitirá fácilmente ofrecer datos objetivos (indicadores) sobre distintos puntos: número total de denuncias recibidas, porcentaje de denuncias investigadas y rechazadas, número de denuncias de buena y mala fe, tipologías denunciadas más y menos frecuentes, cargo o nivel del denunciado, modalidad del contrato laboral (indefinido o temporal) (Open Compliance and Ethics Group, 2012, p. 138), localización geográfica de los hechos irregulares, tiempo que pasa desde que se realiza la denuncia hasta que se concluye la investigación, etc. Los indicadores serán objeto de monitoreo a lo largo del tiempo para ver su evolución.

Estas evidencias y datos son relevantes en dos planos. Primero, como constatación en sede judicial de los esfuerzos realizados por la empresa para la prevención e identificación de irregularidades de forma eficaz (World Compliance Association, 2019, p. 112). Segundo, las evidencias y datos son valiosos para retroalimentar y mejorar el programa de cumplimiento. Por ejemplo, si todas las denuncias se producen por hechos que ocurren en una de las empresas filiales que opera en el exterior, se deberán reforzar los mecanismos de control en tal localización. Si todos los hechos denunciados son atribuibles a personal de la alta dirección, resultará claro que existe un deficiente control sobre este tipo de personal y que es muy cuestionable el compromiso de los apicales de la organización con el compliance.

Es importante que el funcionamiento del canal denuncias y la realización de investigaciones internas refleje el esfuerzo real de la organización por detectar irregularidades (Jorge Gili, 2019, p. 302). A través de la constitución de un repositorio de evidencias, se puede dejar constatación de las actuaciones llevadas al efecto en tal sentido. Para ello, se recopilarán evidencias electrónicas (archivos, documentos, correos electrónicos), documentación en soporte escrito (informes, actas, cartas, faxes, facturas, contratos) y otro tipo de archivos (fotografías, grabaciones de audio y video). En todos esos casos, se buscará que tengan sello de tiempo y

PAUTASY

RECOMENDACIONES

TÉCNICO-

JURÍDICAS PARA LA

CONFIGURACIÓN

DE UN CANAL

DE DENUNCIAS

EFICAZEN

ORGANIZACIONES

PÚBLICAS Y

PRIVADAS. LA

PERSPECTIVA

ESPAÑola

TECHNICAL AND

LEGAL GUIDELINES

AND RECOMMEN-

DATIONS FOR

THE CREATION

OF EFFECTIVE

COMPLAINTS

CHANNELS

IN PUBLIC

AND PRIVATE

ORGANIZATIONS.

THE SPANISH

PERSPECTIVE 
rubrica para garantizar la identidad de los intervinientes y la fecha de la generación de la evidencia.

- ¿Las denuncias son remuneradas? Es conveniente abrir el debate sobre la conveniencia de la delación remunerada en causas graves de corrupción (Amoedo Barreiro, 2017, p. 8). Para ello, podemos aprovechar la experiencia de los Estados Unidos.

La Comisión de Bolsa y Valores de los Estados Unidos batió récord en 2018 respecto al número de pistas que recibió de alertadores (5200 notificaciones), cifra que supone un incremento del $76 \%$ respecto a las denuncias recibidas en el año 2012. Estas denuncias han generado para las arcas públicas estadounidenses USD 1400 millones y, en buena medida, este éxito ha sido propiciado por los USD 326 millones invertidos en remunerar a 59 denunciantes (Hernández, 2018).

Por ejemplo, el bounty program en Estados Unidos es un mecanismo que se activa en el caso de que la sanción económica al infractor supere el millón de dólares. La recompensa oscilará entre el $10 \%$ y el $30 \%$ del total recaudado. No podrán beneficiarse de dicha recompensa aquellas personas que están obligadas a reportar operaciones sospechosas a la Securities and Exchange Commission (SEC). En consecuencia, quedan excluidos los abogados, los miembros del área de cumplimiento, los auditores y aquellos funcionarios extranjeros que tengan obligación de reporte. Además, la información aportada por el delator debe ser: a) original (que no sea de dominio público o ya pertenezca a la SEC); b) útil (apropiada y detallada); y c) creíble, actual y suficiente para poder realizar una investigación con viabilidad (Carrión Zenteno, 2014. p. 92).

Asimismo, el motivo que debe alentar al denunciante no resulta pacífico dentro de la doctrina. Para unos, la causa debe ser el deber moral o legal de hacerlo y la actuación conforme a valores éticos ${ }^{24}$; para otros, no importa cuál sea este motivo y ni siquiera sería necesaria la buena $\mathrm{fe}^{25}$. Para Bouville (citado por Pérez Treviño, 2018):

24 En contra de la delación remunerada, Gimeno Bevia (2018) señala que con este instrumento se incrementa el riesgo de transformar a la sociedad «en un auténtico gran hermano en el que los delatores "de buena fe" - o informantes cívicos, [...] se conviertan en auténticos cazarrecompensas o bounty hunters y sustituyan una colaboración ética con las autoridades por otra de carácter puramente avaricioso» (p. 2).

25 En palabras de Pellicer García (2017): “considero que el requerimiento de "buena fe" del alertador es un absurdo. Una información que pueda revelar casos de corrupción, abusos o malas prácticas tiene, [...] el mismo interés público sea cual sea la intención inicial del alertador» (p. 8). 
Si alguien me salva la vida por venganza, ¿no debería decir 'gracias' en lugar de esto estaba mal, nunca lo hagas de nuevo'? Aunque uno puede argumentar que salvar mi vida por las razones correctas es mejor que salvar mi vida por razones equivocadas, es bastante obvio que salvarme es mejor que no hacerlo. Tomar la decisión correcta por la razón equivocada sigue siendo la decisión correcta (p. 288).

La delación remunerada ${ }^{26}$, al igual que el anonimato, se presentan como formas necesarias y proporcionadas cuando el denunciante realmente se encuentra ante casos de una magnitud mayúscula en lo económico, en los que los acusados son personas relevantes en lo político o en lo económico, o cuando exista un serio riesgo para la vida del denunciante. Es decir, atendiendo a las cuantías del delito, la peligrosidad o importancia del delincuente y los bienes jurídico-penales en conflicto, se debe facilitar la denuncia a través de herramientas que propicien el anonimato ${ }^{27}$ y que motiven al denunciante a través de estímulos (remuneración) ${ }^{28}$; caso contrario, es muy difícil que las personas arriesguen su vida. La corrupción realmente mata y el hombre promedio no debe ser ningún héroe.

Por ejemplo, en Malta, la periodista de investigación Daphne Caruana fue asesinada como consecuencia de una bomba que instalaron en su vehículo. La periodista había sido el azote del Pilatus Bank al destapar un caso de blanqueo de capitales y corrupción que implicaba tanto al banco y a su expresidente como a miembros del Gobierno o sus familiares. Hasta USD 115 millones se movieron irregularmente a través de Venezuela (Val, 2017). En Colombia también se han producido muertes sospechosas de testigos claves en el caso Odebrecht, como las de Rafael Merchán (supuesto suicidio por cianuro), Jorge Enrique Pizano (aparente infarto) y su hijo, Alejandro Pizano (envenenamiento por cianuro) (Betín, 2018). En Eslovaquia, el periodista Ján Kuciak y su novia fueron asesinados cuando el primero se disponía a publicar un artículo en el que se

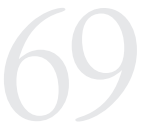

PAUTAS Y

RECOMENDACIONES

TÉCNICO-

JURÍDICAS PARA LA

CONFIGURACIÓN

DE UN CANAL

DE DENUNCIAS

EFICAZEN

ORGANIZACIONES

PÚBLICASY

PRIVADAS. LA

PERSPECTIVA

ESPAÑOLA

TECHNICAL AND

LEGAL GUIDELINES

AND RECOMMEN-

DATIONS FOR

THE CREATION

OF EFFECTIVE

COMPLAINTS

CHANNELS

IN PUBLIC

\section{AND PRIVATE}

ORGANIZATIONS.

THE SPANISH

PERSPECTIVE

26 Los inspectores de Hacienda en España, en un buen porcentaje, se muestran a favor de ofrecer recompensas económicas para aquellos que revelen información sobre delitos tributarios (Inspectores de Hacienda del Estado, 2014, p. 12). En el ámbito del contrabando, está permitida la remuneración a los denunciantes conforme a lo estipulado en la Ley Orgánica 12/1995, de 12 de diciembre, de Represión del Contrabando, en su Disposición adicional segunda.

27 Hay soluciones tecnológicas para poder garantizar el anonimato, por ejemplo, Tor, Vitalia, Disconnect, FreeNet, I2P, TunnelBear, Yandex, PaperBus, Whonix o UltraSurf.

28 Apoyaría esta hipótesis la experiencia comparada. Para García Moreno (2014), «la experiencia demuestra que los sistemas de denuncia que tradicionalmente mejores resultados han obtenido son aquellos que ofrecían a cambio de la información un porcentaje de los fondos recuperados gracias a la denuncia» (p. 58) 
afirmaba el vínculo corrupto entre la mafia italiana y los políticos eslovacos (Agencia de Noticias AFP, 2018).

La denuncia confidencial motivada en principios altruistas es suficiente para casos de gravedad leve o media, pero no para casos de la dimensión de los hechos enunciados ${ }^{29}$. La delación remunerada ayudaría a impulsar las denuncias y, además, permitiría que los denunciantes, si lo desean, cambien de forma de vida, país de residencia, trabajo o, simplemente, contraten servicios de seguridad privados para garantizar su integridad o, al menos, reducir su exposición a los riesgos. El dinero les abre la posibilidad de una mayor tranquilidad.

\section{CONCLUSIONES}

- La última década se ha caracterizado en España por la revelación en los medios de comunicación de multitud de casos de corrupción que han exasperado a la ciudadanía, provocando desafección con las instituciones. Consecuencia de dicho clima, organismos internacionales y nacionales han venido recomendando y legislando sobre la necesidad de implementar canales de denuncia en las organizaciones públicas y privadas. España aún no dispone estatalmente de una normativa para la protección efectiva de los denunciantes, mientras que países de su entorno, como Italia, Francia, Países Bajos o Reino Unido, ya disponen de ella desde hace años.

- Dentro del ámbito autonómico, una de las pocas Comunidades que han legislado sobre las denuncias internas es Castilla y León. En esa línea, la Ley 2/2016, de 11 de noviembre, es una iniciativa interesante, pero insuficiente. El estudio de su articulado nos ha revelado que su estándar es poco exigente y tiene serias limitaciones, lo que la aleja de la posibilidad de convertirse en una regulación que realmente estimule las denuncias y proteja a los denunciantes de forma efectiva. Posiblemente por ello, al día de hoy, se ha aplicado en contadas ocasiones. La futura reforma de la ley y la creación de una Agencia Contra la Corrupción y el Fraude en Castilla y León ayudarán a incrementar la persecución eficaz de la delincuencia en el ámbito público de la región, previsiblemente.

- En el año 2016 el Grupo Parlamentario Ciudadanos presentó una Proposición de Ley Integral de Lucha contra la Corrupción y Protección de los Denunciantes para intentar colmar un vacío regulatorio que aún persiste en el sector público. La citada proposición se vertebra sobre dos ejes: a) el reconocimiento de

29 Para una posición a favor de los canales de denuncia anónimos, ver Alapont (2019, p. 17) 
derechos a los denunciantes desde una perspectiva integral; $\mathrm{y}$ b) la creación de una Autoridad Independiente de Integridad Pública que garantice la recta e íntegra actuación en el sector público. Sin duda, esta propuesta hubiera supuesto un paso adelante en la lucha contra la corrupción.

- La Directiva (UE) 2019/1937, de 23 de octubre de 2019, relativa a la protección de las personas que informen sobre infracciones del derecho de la Unión, supone un avance notable para la protección de los denunciantes dentro de la Unión Europea, siempre y cuando se denuncien hechos que se enmarquen en las esferas competenciales de la misma. La Directiva ofrece pautas y recomendaciones concretas para configurar los canales de denuncia; y, además, permite las denuncias anónimas, configura un marco amplio de protección frente a represalias y recoge tres tipos de canales de comunicación de irregularidades (internos, externos y revelaciones públicas).

- Dentro de la normativa española, la Ley 10/2010, de 28 de abril, de Prevención del Blanqueo de Capitales y la Financiación del Terrorismo, es una de las normas más avanzadas a la hora de ofrecer pautas para configurar un canal de denuncias dentro de un marco sectorial concreto. Esta regulación permite las denuncias anónimas y obliga a capacitar a los empleados en el uso del canal interno de denuncias. La no implementación de un canal de denuncias en los sujetos obligados puede suponer una multa de hasta $€ 60000$.

- En el ámbito privado, la norma UNE-ISO 19600, Sistemas de Gestión de Compliance, y la norma UNE 19601, sobre Sistemas de gestión de compliance penal, ofrecen los más altos estándares técnicos para diseñar, implementar y revisar programas de cumplimiento idóneos y efectivos. En consecuencia, las pautas y recomendaciones que ofrecen dichas normas sobre los canales de denuncia son imprescindibles para cualquier organización que pretenda disponer de un canal de denuncias eficaz. En ese sentido, basta señalar que ambas normas permiten las denuncias anónimas e inciden en la importancia de la capacitación de los empleados sobre el uso y las garantías del canal.

- La determinación de la eficacia del canal de denuncias no es una cuestión sencilla. La exigua mención recogida en el Código Penal obliga a evaluar los canales de denuncia desde la ponderación concreta de una serie de criterios o pautas que hemos ido observando en todas las referencias normativas analizadas. Entre otras cuestiones, hay que evaluar: el nivel de protección de los denunciantes, la amplitud del ámbito material y subjetivo,

PEUTASY
RECOMENDACIONES
TÉCNICO-
JURIDICAS PARA LA
CONFIGURACIÓN
DE UN CANAL
DE DENUNCIAS
EFICAZ EN
ORGANIZACIONES
PÚBLICASY
PRIVADAS. LA
PERSPECTIVA
ESPAÑOLA
TECHNICALAND
LEGAL GUIDELINES
AND RECOMMEN-
DATIONS FOR
THE CREATION
OF EFFECTIVE
COMPLAINTS
CHANNELS
IN PUBLIC
AND PRIVATE
ORGANIZATIONS.
THE SPANISH
PERSPECTIVE


la confidencialidad o anonimato, el carácter potestativo u obligatorio de la denuncia, la formación y capacitación en el uso del canal, etc. En definitiva, la determinación de la eficacia de un canal es una tarea compleja que exige la evaluación particular de las condiciones que caracterizan el canal de denuncias, así como de las políticas y procedimientos que le acompañan. Solo así podremos valorar su grado de eficacia.

\section{REFERENCIAS}

Agencia de Noticias AFP. (28 de febrero de 2018). El periodista eslovaco asesinado investigaba vínculos entre políticos y la mafia italiana. El País. Recuperado de https://lpais.com/internacional/2018/02/28/actualidad/1519817411_439690.html

Agencia de Noticias EFE. (2 de septiembre de 2019). La Junta tramita 3 denuncias internas de funcionarios por posible corrupción. La Vanguardia. Recuperado de https://www.lavanguardia.com/politica/20190902/47144662267/la-junta-tramita-3denuncias-internas-de-funcionarios-por-posible-corrupcion.html

Agencia de Noticias ICAL. (25 de julio de 2019). La Junta de Castilla y León ampliará la protección de los denunciantes de corrupción en la administración. Ileón. Recuperado de https://wwwileon.com/politica/099886/la-junta-de-castillay-leon-ampliara-la-proteccion-de-los-denunciantes-de-corrupcion-en-laadministracion

Agencia de Noticias ICAL. (8 de agosto de 2020). Igea se da un año para poner en marcha la Agencia de Prevención y Lucha contra el Fraude y la Corrupción en Castilla y León. Ileón. Recuperado de https://www.leon.com/ castilla_y_leon/110606/igea-se-da-un-ano-para-poner-en-marcha-la-agenciade-prevencion-y-lucha-contra-el-fraude-y-la-corrupcion-en-castilla-y-leon

Alapont, J. L. (2019). Criminal compliance. Análisis de los arts. 31 bis 2 a 5 CP y 31 quater CP. Revista General de Derecho Penal, (31).

Amoedo Barreiro, D. (2017). Elementos esenciales para un sistema de protección de denunciantes. Revista Internacional Transparencia e Integridad, (4), 1-8. Recuperado de https://revistainternacionaltransparencia.org/wp-content/ uploads/2017/09/Daniel-Amoedo.-.pdf

Antón Teixido, J. (2019). Indicadores y reporting. En X. Ribas (dir.), Practicum Compliance 2020 (pp. 349-390). Navarra: Aranzadi.

Asociación Española de Compliance (ASCOM). (2016). Materiales para la preparación de la Certificación Cescom. Madrid: Asociación Española de Compliance.

Asociación Española de Compliance (ASCOM). (2017). Libro blanco sobre la función de Compliance. Madrid: Asociación Española de Compliance. Recuperado de https://www.asociacioncompliance.com/wp-content/uploads/2017/08/LibroBlanco-Compliance-ASCOM.pdf

Bachmaier Winter, L. (2019). Whistleblowing europeo y compliance: La Directiva EU de 2019 relativa a la protección de personas que reporten infracciones del Derecho de la Unión. Diario La Ley, (9539). 
Bachmaier Winter, L., \& Martínez Santos, A. (2019). El régimen jurídico-procesal del whistleblower. La influencia del Derecho europeo. En J. L. Gómez Colomer (dir.), Tratado sobre compliance penal. Responsabilidad Penal de las Personas Jurídicas y Modelos de Organización y Gestión (pp. 503-550). Valencia: Tirant lo Blanch.

Balmaceda Hoyos, G., Guerra Espinosa, R., \& Juppe Ewing, M. F. (2019). Compliance. Visión general desde una perspectiva penal y comercial. Santiago de Chile: Thompson Reuters.

Benítez Palma, E. (2018). El control externo y el whistleblowing (canales de denuncia). Revista Española de Control Externo, XX(59), 11-42.

Bermejo, M. G. (2013). Delincuencia empresarial: la regulación del informante interno (whistleblower) como estrategia político criminal. Revista Derecho Penal, (4), 49-75.

Betín, T. (23 de diciembre de 2018). La novela negra tras la muerte de Jorge Pizano. El Heraldo. Recuperado de https://www.elheraldo.co/colombia/la-novelanegra-tras-la-muerte-de-jorge-pizano-580958

Campos Acuña, M. C. (2018). Whistleblower: análisis del denunciante de buena fe en el ordenamiento jurídico español. El Consultor de los Ayuntamientos y de los juzgados: Revista técnica especializada en administración local y justicia municipal, (12), 130-138.

Carrión Zenteno, A. (2014). Criminal compliance. Lima: ECB Ediciones.

Casos aislados de una corrupción sistémica (s.f.). Inicio [Base de datos de casos de corrupción en España]. Recuperado de https://www.casos-aislados.com/

CerrilloiMartínez,A. (2018).Diezpropuestasparalacolaboraciónciudadanaenlaalerta de malas prácticas en la Administración Pública. Revista Internacional de Transparencia e Integridad, (6), 1-7. Recuperado de https://revistainternacionaltransparencia.org/wpcontent/uploads/2018/04/agusti_cerrillo.pdf

Comisión Europea. (2017). Comunicación de la Comisión al Parlamento Europeo, al Consejo, al Comité Económico y Social Europeo y al Comité de las Regiones. Conseguir que la contratación pública funcione en Europa y para Europa (COM/2017/0572 final). Recuperado de https:/eur-lex.europa.eu/legal-content/ES/ TXT/?uri=CELEX\%3A52017DC0572

De La Nuez Sánchez-Cascado, E. (6 noviembre, 2019). La nueva directiva europea de protección del denunciante de corrupción y su transposición al Derecho español. Fundación Hay Derecho. Recuperado de https:/hayderecho. expansion.com/2019/11/06/la-nueva-directiva-europea-de-proteccion-deldenunciante-de-corrupcion-y-su-transposicion-al-derecho-espanol/

Del Rosal Blasco, B. (2018). Manual de responsabilidad penal y defensa penal corporativas. Madrid: Wolters Kluwer.

Del Val, J. (7 de junio de 2019). El acoso laboral en las Administraciones Públicas. Administraciones Públicas y su Personal. Recuperado de https:// administracionespublicas.wordpress.com/2019/06/07/el-acoso-laboral-en-lasadministraciones-publicas/

PAUTASY

RECOMENDACIONES TÉCNICO-

JURÍDICAS PARA LA

CONFIGURACIÓN

DE UN CANAL

DE DENUNCIAS

EFICAZ EN

ORGANIZACIONES

PÚBLICASY

PRIVADAS. LA

PERSPECTIVA

ESPAÑOLA

TECHNICAL AND

LEGAL GUIDELINES

AND RECOMMEN-

DATIONS FOR

THE CREATION

OF EFFECTIVE

COMPLAINTS

CHANNELS

IN PUBLIC

AND PRIVATE

ORGANIZATIONS.

THE SPANISH

PERSPECTIVE 
Fernández González, M. C. (2019). El whistleblower en España: un análisis criminológico en la eficacia de proteger o premiar al alertador. En O. Capdeferro Villagrasa (coord.), Compliance urbanístico (pp.163-184). Navarra: Aranzadi.

Ferré Olivé, J. C. (2017). Instrumentos internacionales en la lucha contra la corrupción. En M. del C. Gómez Rivero y A. Barrero Ortega (dirs.), Regeneración democrática y estrategias penales en la lucha contra la corrupción (pp. 483-508). Valencia: Tirant lo Blanch.

Fundación Hay Derecho (s.f.) Comparativa autonómica. Recuperado de https:// hayderecho.com/protegiendo-a-los-valientes/comparativa-autonomica/

García Moreno, B. (2014). Whistleblowing como formade prevención de lacorrupción en la Administración. En A. Nieto Martín y M. Maroto Calatayud (coords.), Public compliance: prevención de la corrupción en administraciones públicas y partidos políticos (pp. 43-60). Cuenca: Ediciones de la Universidad Castilla-La Mancha.

García Moreno, B. (2015). Whistleblowing y canales institucionales de denuncia. En A. Nieto Martín (dir.), Manual de cumplimiento penal en la empresa (pp. 206-230). Valencia: Tirant Lo Blanch.

García San Martín, J. (2020). Doctrina Penal Actualizada (2da edición). Valencia: Tirant lo Blanch.

Gimeno Bevia, J. (2018). De falciani a birkenfeld: la evolución del delator en un cazarrecompensas. Aspectos procesales e incidencia frente a las personas jurídicas (whistleblower vs bounty hunter). Diario La Ley, (9139).

Güemes, C. (2018). La corrupción y la (des)confianza como normas sociales. Cambio de enfoque, nuevas perspectivas. Revista Internacional Transparencia e Integridad, (6), 1-7. Recuperado de https://revistainternacionaltransparencia.org/ wp-content/uploads/2018/04/cecilia_guemes.pdf

Goñi Sein, J. L. (2011). Sistemas de denuncia interna de irregularidades ("whistleblowing”). En J. L. Goñi Sein (dir.), Ética empresarial y códigos de conducta (pp. 319-355). Madrid: La Ley.

Gosálbez Pequeño, H. (2019). Los denunciantes como instrumento de lucha contra la corrupción: a propósito de la denuncia administrativa en las leyes «anticorrupción». Actualidad Administrativa, (Extra 1).

Gutiérrez Pérez, E. (2018). Corrupción pública: concepto y mediciones. Hacia el Public compliance como herramienta de prevención de riesgos penales. Política Criminal, 13(25), 104-143. https://doi.org/10.4067/S0718-33992018000100104

Hernández, J. (16 de diciembre de 2018). Proteger a los denunciantes de corrupción reporta 1.400 M. a la CNMV estadounidense. Voz Populi. Recuperado de https:// www.vozpopuli.com/economia-y-finanzas/empresas/proteger-denunciantescorrupcion-Gobierno-EEUU_0_1199580198.html

Hersh, M. (2002) Whistleblowers - Heroes or traitors? Individual and collective responsibility for ethical behaviour. Annual Review in Control, 26(2), 243-262. https://doi.org/10.1016/S1367-5788(02)00025-1 
Inspectores de Hacienda del Estado. (2014). El grave problema de la corrupción en España. En XXIV Congreso Anual de Inspectores de Hacienda. Recuperado de https:// www.inspectoresdehacienda.org/doc/Documento_Cogreso_Bilbao_2014.pdf

Jiménez Sánchez, F. (2017). Los efectos de la corrupción sobre la desafección y el cambio político en España. Revista Internacional Transparencia e Integridad, (5), 1-16. Recuperado de https://revistainternacionaltransparencia.org/wp-content/ uploads/2017/12/fernando_jimenez.pdf

Jorge Gili, J. (2019). Investigaciones internas. En X. Ribas (dir.), Practicum Compliance 2020 (pp. 297-308). Navarra: Aranzadi.

Lapuente, V. (2018). Introducción: España en el diván. En V. Lapuente (coord.), La calidad de las instituciones en España (pp. 13-41). Madrid: Círculo de Empresarios, Transparency International España.

Leo Castela, J. I. (2018). Compliance y whistleblowing en América Latina: el tratamiento en los medios de la corrupción transnacional. En AA. VV., Justicia penal pública y medios de comunicación (pp. 657-679). Valencia: Tirant lo Blanch.

Lousada Arochena, J. F. (2019). Sistemas de denuncias internas (Whistleblowing) y derechos fundamentales en el trabajo. Revista Trabajo y Derecho, (52), 24-36.

Lozano Cutanda, B. (2020). La directiva de protección del denunciante. Diario La Ley, (9550).

Moretón Toquero, M. A. (2017). Partidos políticos, corrupción y transparencia. En M. del C. Gómez Rivero y A. Barrero Ortega (dirs.), Regeneración democrática y estrategias penales en la lucha contra la comrupción (pp. 175-208). Valencia: Tirant lo Blanch.

Nieto Martín, A., \& García Moreno, B. (coords.) (2018). Guía para la prevención de la corrupción en las Administraciones Públicas de Castilla-La Mancha. Cuenca: Ediciones de la Universidad de Castilla-La Mancha. Recuperado de https:// ruidera.uclm.es/xmlui/bitstream/handle/10578/18471/GUIA_PREVENCION_ CORRUPCION.pdf?sequence $=1$ \& isAllowed $=y$

Nieto Martín, A., \& García Moreno, B. (2019). De la ética pública al public compliance: sobre la prevención de la corrupción en las Administraciones públicas. En J. L. Gómez Colomer (dir), Tratado sobre compliance penal. Responsabilidad Penal de las Personas Jurídicas y Modelos de Organización y Gestión (pp. 379-407). Valencia: Tirant lo Blanch.

Ordóñez Solís, D. (2017). ¿Ciudadanos, soplones y príncipes clementes en una sociedad democrática? Revista de Derecho UNED, (21), 41-71. Recuperado de http:// e-spacio.uned.es/fez/eserv/bibliuned:RDUNED-2017-21-5005/Ordonez_Solis.pdf

Open Compliance and Ethics Group (OCEG). (2012). OCEG Red Book. GRC Capability Model, versión 2.1. Recuperado de https://thegrcbluebook.com/wpcontent/uploads/2013/03/uploads_Red-Book.2.1.optimized_0.pdf

Organización de Cooperación y Desarrollo Económico (OCDE). (2016). Committing to Effective Whistleblower Protection. París: OECD Publishing.

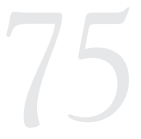

PAUTAS Y

RECOMENDACIONES TÉCNICO-

JURÍDICAS PARA LA

CONFIGURACIÓN

DE UN CANAL

DE DENUNCIAS

EFICAZ EN

ORGANIZACIONES

PÚBLICASY

PRIVADAS. LA

PERSPECTIVA

ESPAÑOLA

TECHNICAL AND

LEGAL GUIDELINES

AND RECOMMEN-

DATIONS FOR

THE CREATION

OF EFFECTIVE

COMPLAINTS

CHANNELS

IN PUBLIC

AND PRIVATE

ORGANIZATIONS.

THE SPANISH

PERSPECTIVE 
Organización de Cooperación y Desarrollo Económico (OCDE). (2018). State-Ouned Enterprises and Cormuption: What Are the Risks and What Can Be Done?, París: OECD Publishing. Recuperado de https://www.oecd-ilibrary.org/ governance/state-owned-enterprises-and-corruption_9789264303058-en

Organización de Cooperación y Desarrollo Económico (OCDE). (2019). Directrices en materia de Lucha Contra la Corrupción e Integridad en las Empresas Públicas. Recuperado de http://www.oecd.org/daf/ca/Guidelines-AntiCorruption-Integrity-State-Owned-Enterprises-ES.pdf

PellicerGarcía,J.L. (2017).Herramientas y propuestas paraluchar contrala corrupción enelsectorpúblico:ética, transparenciaycompliance. RevistaInternacional Transparencia e Integridad, (5), 1-9. Recuperado de https://revistainternacionaltransparencia.org/wpcontent/uploads/2017/12/jose_luis_pellicer.pdf

Pérez Treviño, J. L. (2018). Whistleblowing. Eunomía: Revista en Cultura de la Legalidad, (14), 285-298. https://doi.org/10.20318/eunomia.2018.4170

Pérez Monguió, J. M. (2019). La irrupción del Estatuto del denunciante: un instrumento del buen gobierno para la lucha contra la corrupción. En F. Castillo (coord.), Compliance e integridad en el sector público (pp. 83-114). Valencia: Tirant lo Blanch.

Prats Català, J. (2007). La lucha contra la corrupción como parte integrante del Derecho, el deber y las políticas de buena administración. Cuadernos de Derecho Público, (31), 13-30.

Puyol Montero, J. (2017). El funcionamiento práctico del canal de compliance «whistleblowing». Valencia: Tirant lo Blanch.

Ragués i Vallés, R. (2017). ¿Es necesario un estatuto para los denunciantes de la corrupción? Diario La Ley, (9003).

Sibina Tomàs, D., \& Arnal Arasa, E. (2008). Crónica de Jurisprudencia: El Tribunal Europeo de Derecho Humanos. Cuadernos de Derecho Local, (18), 157-159. Recuperado de https:/www.gobiernolocal.org/cuadernos-de-derecho-local-no-18/

U.S. Department of Justice Criminal Division. (Junio de 2020). Evaluation of Corporate Compliance Programs. Recuperado de https://www.justice.gov/criminalfraud/page/file/937501/download

Val, E. (7 de diciembre de 2017). La bomba que mató a la periodista maltesa fue activada desde un yate. La Vanguardia. Recuperado de http://www.lavanguardia. com/internacional/20171207/433463679761/asesinato-periodista-maltadaphne-caruana-movil-yate.html

Velasco Núñez, E., \& Saura Alberdi, B. (2016). Cuestiones prácticas sobre responsabilidad penal de la persona jurídica y compliance. 86 preguntas y respuestas. Navarra: Aranzadi.

Vestri, G. (2019). Aproximación al sistema de «whistleblowing». Un nuevo desafío para la Administración Pública española. La Administración al Día. Recuperado de http://aadministracionaldia.inap.es/noticia.asp?id=1509756 
Villoria Mendieta, M. (2018). La Transparencia. En V. Lapuente (coord.), La calidad de las instituciones en España (pp. 187-227). Madrid: Círculo de Empresarios, Transparency International España.

Villoria Mendieta, M. (2019). Gestión pública. Eunomía, (16), 158-172. https://doi. org/10.20318/eunomia.2019.4697

World Compliance Association. (2019). Guía de implementación de compliance para pymes. "Manual práctico de implementación". Recuperado de http://www. worldcomplianceassociation.com/documentacion/Guia_Compliance_web_ compressed.pdf

Wolters Kluwers (s.f.). Canal de denuncias (Concepto). Recuperado de https:// www.guiasjuridicas.es/Content/DocumentoRelacionado.aspx?params $=\mathrm{H} 4$ sIAA AAAAAEAMtMSbF1jTAAAkNjI0NjE7Wy1KLizPw827DM9NS8k1QAIOg4I iAAAAA $=$ WKE

Jurisprudencia, normativa y otros documentos legales Caso Guja contra Moldavia, Demanda 14277/2004, Sentencia (TEDH, Gran Sala, 12 de febrero de 2008). Recuperada de http://hudoc.echr.coe.int/spa?i=001-139375

Constitución Española, texto consolidado actualizado (Cortes Generales [España], 27 de septiembre de 2011.). Boletín Oficial del Estado, (311). Recuperado de https://www.boe.es/buscar/pdf/1978/BOE-A-1978-31229-consolidado.pdf

Convenio Europeo para la Protección de los Derechos Humanos y de las Libertades Fundamentales (TEDH y Consejo de Europa [Roma, Italia], 4 de noviembre de 1950). Recuperado de https://www.echr.coe.int/documents/convention_spa.pdf

Directiva (UE) 2019/1937, relativa a la protección de las personas que informen sobre infracciones del Derecho de la Unión (Parlamento Europeo y del Consejo [UE], 23 de octubre de 2019). Diario Oficial de la Unión Europea, (305). Recuperado de https://www.boe.es/doue/2019/305/L00017-00056.pdf

Legge 30 novembre 2017, n. 179, recante Disposizioni per la tutela degli autori di segnalazioni di reati o irregolarità di cui siano venuti a conoscenza nell'ambito di un rapporto di lavoro pubblico o privato, (17G00193) (Camera dei deputati ed il Senato della Repubblica [Italia], 30 de noviembre de 2017). Gazzetta Ufficiale, Serie Generale, (291). Recuperado de https://www.gazzettaufficiale.it/ $\mathrm{eli} / \mathrm{id} / 2017 / 12 / 14 / 17 \mathrm{G} 00193 / \mathrm{sg}$

Ley 19/2013, de transparencia, acceso a la información pública y buen gobierno (Cortes Generales [España], 9 de diciembre de 2013). Boletín Oficial del Estado, (295). Recuperado de https://www.boe.es/buscar/pdf/2013/BOE-A-2013-12887consolidado.pdf

Ley 5/2014, de Seguridad Privada (Cortes Generales [España], 4 de abril de 2014). Boletín Oficial del Estado, (83). Recuperado de https://www.boe.es/buscar/ pdf/2014/BOE-A-2014-3649-consolidado.pdf

Ley 2/2016, por la que se regulan las actuaciones para dar curso a las informaciones que reciba la Administración Autonómica sobre hechos relacionados con delitos contra la Administración Pública y se establecen las garantías de los informantes

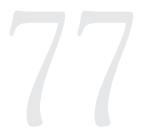

PAUTASY

RECOMENDACIONES

TÉCNICO-

JURÍDICAS PARA LA

CONFIGURACIÓN

DE UN CANAL

DE DENUNCIAS

EFICAZ EN

ORGANIZACIONES

PÚBLICASY

PRIVADAS. LA

PERSPECTIVA

ESPAÑOLA

TECHNICAL AND

LEGAL GUIDELINES

AND RECOMMEN-

DATIONS FOR

THE CREATION

OF EFFECTIVE

COMPLAINTS

CHANNELS

IN PUBLIC

AND PRIVATE

ORGANIZATIONS.

THE SPANISH

PERSPECTIVE 
(Cortes de Castilla y León [España], 11 de noviembre de 2016). Boletín Oficial del Estado, (296). Recuperado de https://www.boe.es/boe/dias/2016/12/08/pdfs/ BOE-A-2016-11673.pdf

Ley Orgánica 3/2018, de Protección de Datos Personales y garantía de los derechos digitales (Cortes Generales [España], 5 de diciembre de 2018). Boletín Oficial del Estado, (294). Recuperado de https://www.boe.es/eli/es/lo/2018/12/05/3/dof/spa/pdf

Norma Española UNE-ISO 19600 (2015). Sistemas de gestión de compliance. Directrices. Madrid: Asociación Española de Normalización y Certificación.

Norma Española UNE-ISO 19601 (2017). Sistemas de gestión de compliance penal. Requisitos con orientación para su uso. Madrid: Asociación Española de Normalización.

Norma Española UNE-ISO 19602 (2019). Sistemas de gestión de compliance Tributario. Requisitos con orientación para su uso. Madrid: Asociación Española de Normalización UNE.

Proposición de Ley Integral de Lucha contra la Corrupción y Protección de los Denunciantes, 122/000022, presentada por el Grupo Parlamentario Ciudadanos (Congreso de los Diputados [España], 20 de septiembre de 2016). Boletín Oficial del Congreso de los Diputados, (B-33-1). Recuperado de http://www.congreso.es/portal/ page/portal/Congreso/PopUpCGI?CMD $=$ VERLST\&BASE $=$ pu12\&FMT $=\mathrm{PU}$ WTXDTS.fmt\&DOCS $=1-1 \& D O C O R D E R=$ LIFO\&QUERY =\%28BOCG12-B-33-1.CODI.\%29\#(P\%C3\%A1gina1)

Real Decreto de 14 de septiembre de 1882 por el que se aprueba la Ley de Enjuiciamiento Criminal (Ministerio de Gracia y Justicia [España], 14 de septiembre de 1882). Boletín Oficial del Estado, (260). Recuperado de https://www. boe.es/buscar/act.php?id=BOE-A-1882-6036

Real Decreto Legislativo 5/2015, por el que se aprueba el texto refundido de la Ley del Estatuto Básico del Empleado Público (Gobierno de España, 30 de octubre de 2015). Boletín Oficial del Estado, (261). Recuperado de https://www. boe.es/buscar/pdf/2015/BOE-A-2015-11719-consolidado.pdf

Real Decreto-ley 11/2018, de transposición de directivas en materia de protección de los compromisos por pensiones con los trabajadores, prevención del blanqueo de capitales y requisitos de entrada y residencia de nacionales de países terceros y por el que se modifica la Ley 39/2015, de 1 de octubre, del Procedimiento Administrativo Común de las Administraciones Públicas (Gobierno de España, 31 de agosto de 2018). Boletín Oficial del Estado, (214). Recuperado de https:// www.boe.es/boe/dias/2018/09/04/pdfs/BOE-A-2018-12131.pdf

Sentencia del Tribunal Supremo, RJ 2001, 8027, que resuelve el Recurso de Casación No 3715/1997 (Sala de lo Contencioso-Administrativo, Sección 6 ${ }^{3}$ [España], 23 de julio de 2001). Recuperado de http:/www.inia.es/gcontrec/ pub/23-07-2001_1195460221656.pdf 